\title{
The Low-Level Atmospheric Circulation near Tongoy Bay-Point Lengua de Vaca (Chilean Coast, $\left.30^{\circ} \mathbf{S}\right)$
}

\author{
DAVID A. RAHN AND RENÉ D. GARREAUd \\ Departamento de Geofísica, Facultad de Ciencias Físicas y Matemáticas, Universidad de Chile, Santiago, Chile \\ JosÉ A. RutLLANT \\ Departamento de Geofísica, Facultad de Ciencias Físicas y Matemáticas, Universidad de Chile, Santiago, \\ and Centro de Estudios Avanzados en Zonas Áridas, La Serena, Chile
}

(Manuscript received 1 March 2011, in final form 25 April 2011)

\begin{abstract}
Strong southerly, terrain parallel winds often occur along the coast of north-central Chile $\left(25^{\circ}-35^{\circ} \mathrm{S}\right) \mathrm{em}$ bedded in the marine atmospheric boundary layer and the lower part of the capping temperature inversion. Their offshore structure and variability have received considerable attention because of the effect on openocean processes and connection with the southeast Pacific cloud layer. Mesoscale low-level circulations linked to the coastal topography (e.g., coastal jets and sea breeze) are less studied in Chile, but are particularly relevant as they alter the upper-ocean circulation and the cloud pattern in the nearshore strip.

Surface, radiosonde, and airborne meteorological observations near point Lengua de Vaca (LdV)-Tongoy Bay (TB) at $30^{\circ} \mathrm{S}$ are used alongside numerical modeling to understand the local circulation near a prominent upwelling center. Most observations were gathered during the Variability of the American Monsoon Systems (VAMOS) Ocean-Cloud-Atmosphere-Land Study Chilean Upwelling Experiment (VOCALS-CUpEx) during two weeks in late spring 2009. The regional topography resembles other major capes, but south of TB and east of LdV there is a low $(100-300 \mathrm{~m})$, dry marine terrace bounded by high elevation at the coast $(\sim 600 \mathrm{~m})$ and farther inland. Coastal soundings $25 \mathrm{~km}$ upstream of LdV revealed a southerly wind maximum near the surface and another at $900 \mathrm{~m}$ separated by a destabilized layer, deviating from the two-layer model often applied to coastal flow. In the morning a shallow sea breeze penetrates from TB to the marine terrace, but is overridden by southerly flow in the afternoon. Furthermore, between 400 and $900 \mathrm{~m}$, warm continental air is advected from over the marine terrace creating a residual boundary layer over TB. Concurrent with slower changes offshore, the low-level warming over TB leads to a marked cross-shore pressure gradient enhancing the coastal jet just north of LdV.
\end{abstract}

\section{Introduction}

The coast of north-central Chile $\left(20^{\circ}-35^{\circ} \mathrm{S}\right)$ along the western edge of South America exhibits the typical characteristics of eastern boundary upwelling systems (EBUS) at subtropical latitudes (Hill et al. 1998) and its climate is largely dominated by the southeast Pacific (SEP) anticyclone producing stable, semiarid conditions. This region also exhibits a prominent topography, with coastal mountains ranging from $500-1500 \mathrm{~m}$ and the Andes cordillera rising up to $5000 \mathrm{~m}$ only $200-300 \mathrm{~km}$ inland.

Corresponding author address: David A. Rahn, Departamento de Geofísica, Universidad de Chile, Blanco Encalada 2002, Santiago, Chile.

E-mail: darahn@gmail.com
Equatorward flow (southerly wind) prevails in the lower troposphere and fosters upwelling of cold waters along the coast. The adiabatic warming aloft and the cold sea surface lead to the development of a well-defined atmospheric marine boundary layer (AMBL) capped by a strong temperature inversion (e.g., Rahn and Garreaud 2010a), a system that is able to maintain one of the most persistent low-level cloud decks in the world (Klein and Hartmann 1993). The AMBL generally deepens offshore, but can have considerable synoptic variability (Garreaud et al. 2001; Rahn and Garreaud 2010b; Jiang et al. 2010). During austral spring and summer (September-March) the SEP anticyclone reaches its southernmost position and sea level pressure (SLP) typically increases southward along the coast. The presence of the coastal range, however, restricts the zonal (cross shore) flow, breaking down the geostrophic 

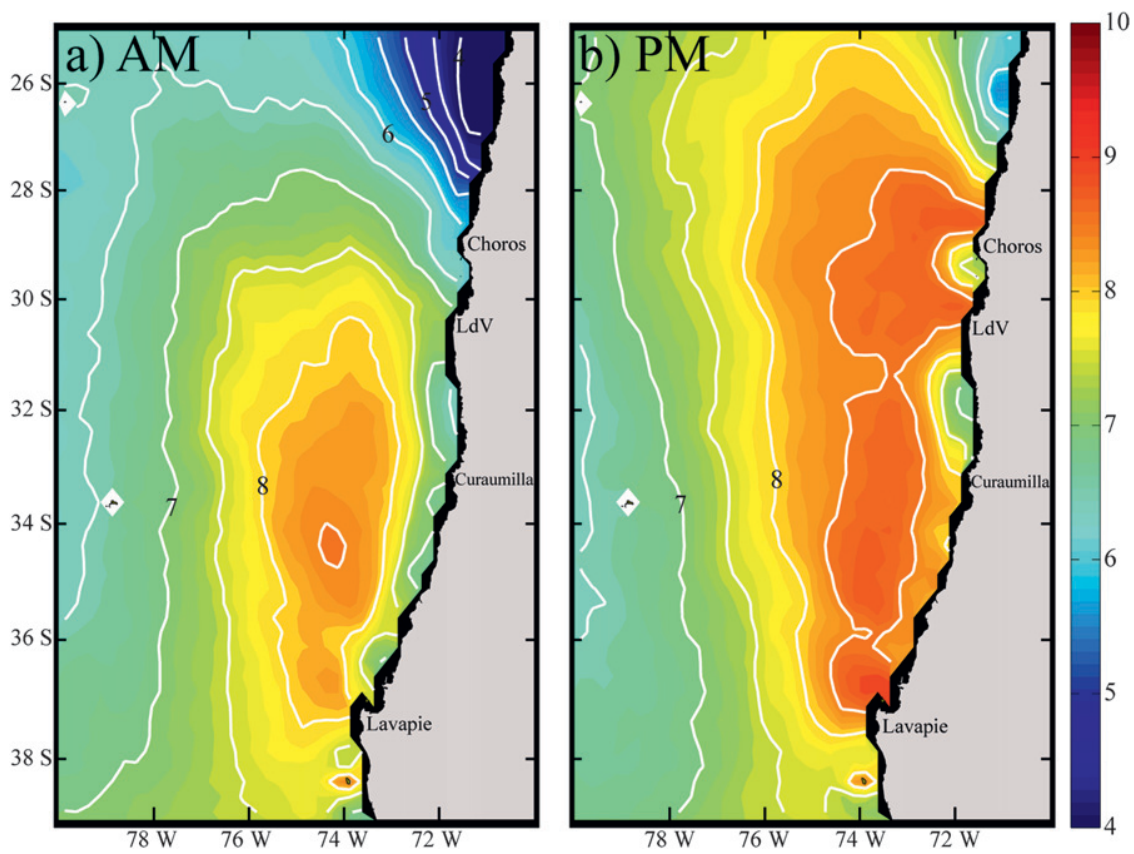

FIG. 1. The 10-m wind derived from QuikSCAT averaged over November and December 1999-2008 for the (a) morning and (b) evening satellite passes.

balance in the meridional (alongshore) direction and leading to the formation of a southerly low-level jet (LLJ) off central Chile (Garreaud and Muñoz 2005; Muñoz and Garreaud 2005). Southerly LLJs are particularly strong when a migratory anticyclone crosses the coast of southern Chile (Garreaud and Muñoz 2005), but a wind speed maximum $\left(>8 \mathrm{~m} \mathrm{~s}^{-1}\right)$ is even evident in the long-term November-December mean over an elongated, coastalparallel area centered about $150 \mathrm{~km}$ offshore (Fig. 1).

Broadly speaking, the Chilean coastline, the adjacent coastal range, and the Andes cordillera are oriented in a north-south direction at subtropical latitudes, which somewhat facilitates the analysis of the offshore LLJ (Muñoz and Garreaud 2005). At a local scale, portions of approximately straight north-south sections of the coastline bounded by the coastal range are interrupted by wide, northwest-facing embayments. Along the central Chilean coast, from south to north, the major points are (see Fig. 1): Lavapie $\left(36^{\circ} \mathrm{S}\right)$, Curaumilla $\left(33^{\circ} \mathrm{S}\right)$, Lengua de Vaca $\left(\mathrm{LdV}, 30^{\circ} \mathrm{S}\right)$, and Choros $\left(28.5^{\circ} \mathrm{S}\right)$, Chile. These points (especially LdV and Lavapie) are recognized as the major upwelling centers along the Chilean coast (e.g., Figueroa and Moffat 2000) presumably in connection with local southerly wind maxima. Indeed, the satellite-derived 10-m wind in Fig. 1b reveals not only the broad offshore LLJ, but also localized, near-coastal wind maxima immediately north (downstream) of such prominent points during the afternoon. We refer to the mesoscale wind maxima associated with these points as coastal jets (CJs) to differentiate them from the broader, synoptic-scale LLJ. The offshore wind during the morning is generally weaker (Muñoz 2008) and shows less alongshore variability (Fig. 1a). Furthermore, visible satellite data reveals areas of minimum low-level cloud frequencies located downstream of those points and capes (González et al. 2007), indicative of topographically induced alongshore variability in AMBL structure.

Given the relevance of the mesoscale atmospheric circulation near the coast for the regional meteorology and oceanography, a field experiment was conducted in November and December 2009 around LdV and Tongoy Bay (TB, $\left.30^{\circ} \mathrm{S}\right)$. The so-called Variability of the American Monsoon Systems (VAMOS) Ocean-CloudAtmosphere-Land Study Chilean Upwelling Experiment (VOCALS-CUpEx; Garreaud et al. 2011) included surface meteorological observations (along the coast, on buoys, and on an island), radiosondes, radar-derived sea surface currents, and ocean currents and temperature from a pair of coastal moorings. The in situ observations have been complemented with airborne meteorological measurements taken during subsequent research flights (see Garreaud et al. 2011). A distinguishing feature of the CUpEx site (Fig. 2) is the existence of a very dry, ${ }^{1}$

\footnotetext{
${ }^{1}$ Mean annual rainfall recorded at 3 stations near the MT (Andacollo, Pachingo, and Ovalle) is less than $13 \mathrm{~cm}$ with the majority of precipitation falling in austral winter. For context, average annual rainfall in California ranges from $40 \mathrm{~cm}$ near Point Conception to $100 \mathrm{~cm}$ at Cape Mendocino.
} 

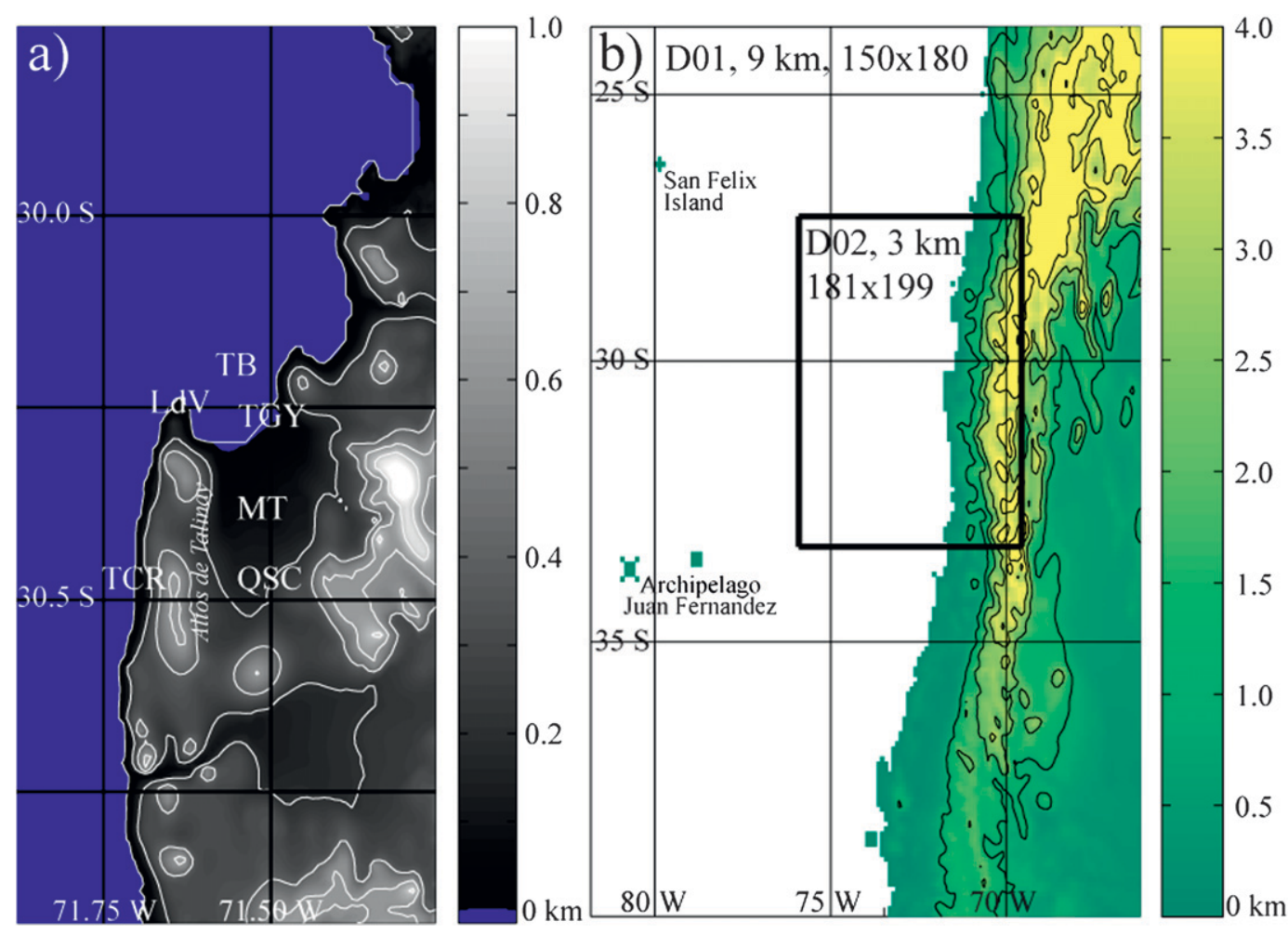

FIG. 2. (a) Elevation map of the CUpEx region (m, shaded and with contours every $200 \mathrm{~m}$ ) including pertinent locations described in text. Elevation obtained from 1-km resolution dataset. (b) Map of model mother domain (D01) and inner domain (D02, bold box). Elevation of topography contoured every $1 \mathrm{~km}$ and shaded by color.

gently sloped, elevated marine terrace (MT) that extends $\sim 30 \mathrm{~km}$ to the south of Tongoy (TGY, $71.5^{\circ} \mathrm{W}$ ) beneath the Altos de Talinay ridge (peak $\sim 600 \mathrm{~m}$ ) at the coast and the foothills farther inland. Farther south, about $100 \mathrm{~km}$ from TGY along $71.5^{\circ} \mathrm{W}$, the terrain peaks $\sim 1000 \mathrm{~m}$ before dropping down at the coast.

The impact of coastal topography on the low-level wind (and hence on upper-ocean circulation) has been studied in other EBUS regions, including the development of regional land-sea temperature contrast, local landsea and mountain-valley breezes, leeside flow, mountain waves, hydraulic flow (expansion fan/compression bulge), and shallow cyclonic eddies. Of particular relevance for our work, observations and simulations reveal a tendency for a flow intensification downwind of the capes that is often interpreted in the form of an expansion fan using hydraulic theory in which the lower troposphere is idealized as a two-layer fluid system (e.g., Winant et al. 1988; Samelson 1992; Burk and Thompson 1996; Rogerson 1999; Burk et al. 1999; Haack et al. 2001). We note, however, that along the west coast of North America, points and capes typically have terrain elevation increasing steadily until well inland. Thus, the terrain is often represented by an unbroken and uniform height increase used in idealized numerical modeling studies (as in Haack et al. 2001; Söderberg and Tjernström 2002; Perlin et al. 2011), a structure different than near LdV-TB.

Diurnal variability of an expansion fan has been explored by Haack et al. (2001) who found the changes in the upstream Froude number and the sea-land breeze modify the leading Mach angle of the expansion fan. A sensitivity test that fixed the surface temperatures to their 1200 UTC value showed that the marine layer wind speed patterns, including a maximum in the lee of two capes, remained largely unchanged throughout the day. Söderberg and Tjernström (2002) demonstrated the influence of varying cross-shore baroclinicity on flow criticality on the hydraulic features. Using a two-way ocean-atmosphere model of an idealized cape, Perlin et al. (2011) examined the diurnal cycle of the wind stress and sea surface temperature and showed that the local evening had the greatest wind stress and spatial gradients, while the intensification in the lee of the cape almost disappears in the morning.

Focus of this work is on two primary objectives. The first is to describe the local characteristics of the mean low-level tropospheric circulation around LdV and TB using meteorological observations obtained during CUpEx. 


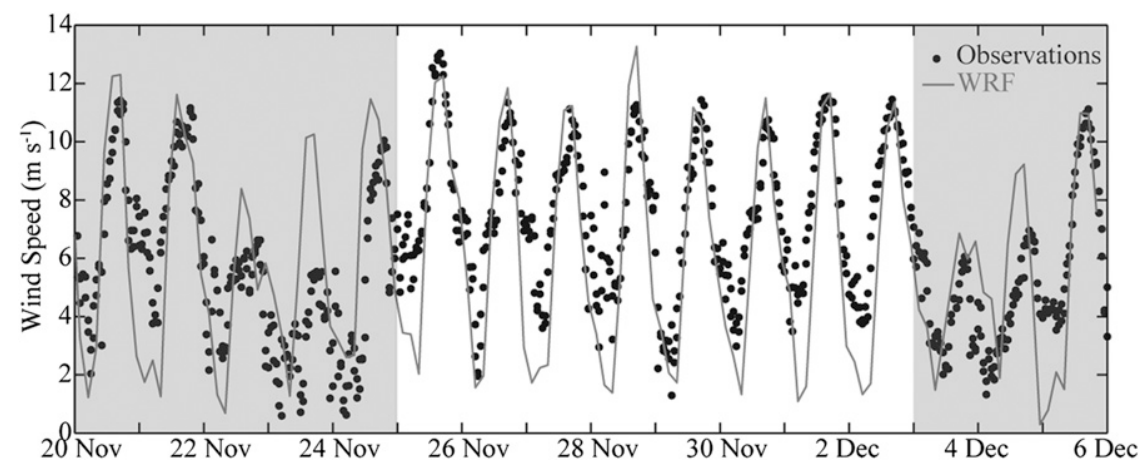

FIG. 3. The 30-min-averaged observed wind speed $\left(\mathrm{m} \mathrm{s}^{-1}\right)$ at $\mathrm{LdV}$ during the intensive phase of the field campaign from observations (black) and WRF (gray). Shaded regions bound the 8day high-wind period.

The observations are supplemented with the results from a high-resolution numerical simulation of the CUpEx period. Once validated against observations, the model results helped us to construct a more comprehensive three-dimensional picture of the mean diurnally varying circulation over this region of complex terrain. As a second objective, the observations and simulation are used to diagnose the dynamical forcing of the $\mathrm{CJ}$ over TB, and compared with similar features along the west coast of North America.

Information on the measurements and numerical simulation is presented in section 2. Observational findings are presented in section 3 and data is synthesized with a numerical simulation to highlight main features in section 4. Included is a sensitivity test modifying the albedo south of TB that explores the impact of the local diurnal radiational heating on the $\mathrm{CJ}$. A summary of the results in section 5 is meant to provide context to the atmospheric forcing on the sea surface (through the surface wind stress field) for subsequent studies on the upwelling and other mesoscale ocean circulations in this region.

\section{Data}

\section{a. Observations}

The intensive observation period of VOCALS-CUpEx took place over two weeks during 21 November5 December 2009 and focused around TB (Fig. 2a). Garreaud et al. (2011) provides a detailed project description and the main observational findings. Key surface meteorology stations used here are point Lengua de Vaca $\left(\mathrm{LdV}: 30.25^{\circ} \mathrm{S}, 71.63^{\circ} \mathrm{W}\right)$ right at the coastal point, Talcaruca (TCR: $30.48^{\circ} \mathrm{S}, 71.70^{\circ} \mathrm{W}$ ) south of $\mathrm{LdV}$ in the north-south-oriented coastline, Tongoy (TGY: $30.26^{\circ} \mathrm{S}$, $71.48^{\circ} \mathrm{W}$ ) in the sheltered TB, and Quebrada Seca (QSC: $30.50^{\circ} \mathrm{S}, 71.49^{\circ} \mathrm{W}, 180 \mathrm{~m}$ ) over the MT west of TCR and south of TGY. Local time (LT) is UTC - $4 \mathrm{~h}$. Radiosondes launched at TCR and TGY took place twice daily near the extremes of the wind diurnal cycle (0800 and 1700 LT), based on previous records at LdV and a modeling study by Muñoz (2008).

To place our results in context, Fig. 3 shows the 3-m wind speed and direction at LdV, highlighting the CUpEx period. Strong afternoon southwest winds $\left(>10 \mathrm{~m} \mathrm{~s}^{-1}\right)$ are prevalent in these months, interrupted by $2-3$ days of relaxed flow with nearly weekly periodicity (Garreaud et al. 2002). During CUpEx we experienced an 8-daylong high-wind period (25 November-2 December) that had regular diurnal cycles and was bounded by low-wind events.

\section{b. Numerical simulation}

Observations are supplemented by the Weather Research and Forecasting model (WRF version 3.1.1; Skamarock et al. 2005). The simulation was initialized at 0000 UTC 20 November 2009 and run continuously until 0000 UTC 6 December 2009, thus covering the full period of CUpEx. Domains were centered over the CUpEx region (Fig. 2b) and included an outer 9-km grid $(150 \times 180$ grid points $)$ and an inner nested $3-\mathrm{km}$ grid $(181 \times 199$ grid points). The vertical grid consists of 56 sigma levels with a top at $50 \mathrm{hPa}(\sim 20 \mathrm{~km})$, a resolution of $\sim 60 \mathrm{~m}$ at $1 \mathrm{~km}$, and $\sim 100 \mathrm{~m}$ at $2 \mathrm{~km}$. Parameterizations are listed in Table 1. Global Forecast System (GFS) analyses $\left(1^{\circ}\right.$ latitude-longitude grid, every $\left.6 \mathrm{~h}\right)$ were used as initial and boundary conditions of the mother domain that continuously nudge the simulation toward the analyses. A relaxation zone extends four grid points into the model domain and blends the model with the analysis that is interpolated linearly to the finer model resolutions. Minimal adjustment is needed when synoptic features are more or less steady, like during the 8 -day high-wind period. Synoptic features are the same 
TABLE 1. WRF parameterizations.

\begin{tabular}{ll}
\hline \hline \multicolumn{1}{c}{ Parameterization } & \multicolumn{1}{c}{ Reference } \\
\hline $\begin{array}{l}\text { Thompson microphysics scheme } \\
\text { Longwave radiation: Rapid radiative } \\
\text { transfer model }\end{array}$ & $\begin{array}{l}\text { Thompson et al. (2004) } \\
\text { Mlawer et al. (1997) }\end{array}$ \\
$\begin{array}{l}\text { Shortwave radiation: Dudhia } \\
\text { Pleim-Xiu land surface model }\end{array}$ & $\begin{array}{l}\text { Dudhia (1989) } \\
\text { Monin-Obukhov (Janjić) } \\
\text { surface scheme }\end{array}$ \\
$\begin{array}{l}\text { Mellor-Yamada-Janjić boundary } \\
\text { layer scheme }\end{array}$ & Janjić (2002) \\
Betts-Miller-Janjić cumulus scheme & Janjić (2002) \\
\hline
\end{tabular}

as in the GFS analysis, but running WRF at a higher resolution resolves the mesoscale features that are needed to assess complex coastal flow.

\section{Observational findings}

\section{a. Surface stations}

The most ample source of observational data comes from surface meteorological stations. While there are long-term stations, several have been installed recently (cf. Table 2 in Garreaud et al. 2011) so focus must be placed on November and December 2009. Average wind vectors at each station are depicted every $6 \mathrm{~h}$ during
November and December 2009 in Fig. 4. A prominent diurnal cycle is found at $\mathrm{LdV}$ where the light wind from the south-southwest (SSW) at $0600 \mathrm{LT}$ increases dramatically by 1800 LT. Similarly, stations south of LdV show a marked increase of the southerly flow during afternoon and, in some locations, the development of an onshore component. At Islote Pajaros, the island north of TGY and about $30 \mathrm{~km}$ from the coast, there is a less pronounced diurnal cycle, and is manifested mainly in wind speed since the direction remains steady. Coastal stations in the bay (and farther inland) exhibit a clearer afternoon breeze directed inland that becomes calm during the night. At TGY and over a buoy in southern TB, the sea-land breeze is manifested as a north-northwest wind from morning to afternoon. Weak northerly winds also reach QSC (30 km south of TGY) during the morning and midday, but they are rapidly overridden by a stronger southerly wind that seems to prevail over the inland MT during afternoon.

During the afternoon, the wind speed is greatest at LdV (SSW in excess of $10 \mathrm{~m} \mathrm{~s}^{-1}$ ) and decays slightly at Islote Pajaros, suggesting the existence of a CJ off TB. This inference is consistent with the satellite measurements that show a local maximum near LdV (Fig. 1b). Neither satellites nor surface observations directly measure the wind maximum in the CJ core above TB. In situ measurements of the CJ immediately north of LdV were

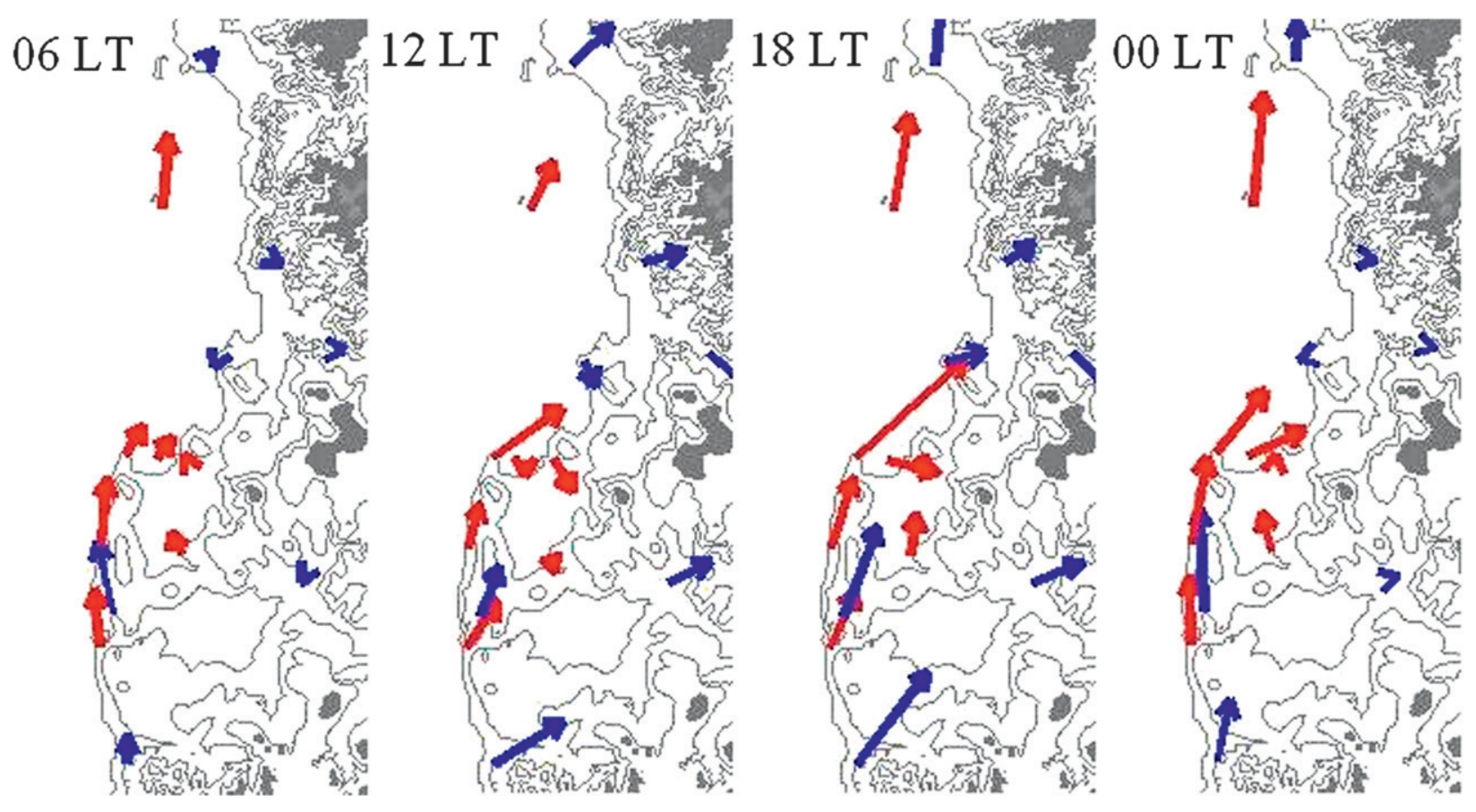

FIG. 4. Mean diurnal cycle of the 10-m winds over the CUpEx area, illustrated by the average wind vectors every 6 h. Red arrows are average winds during CUpEx. Blue arrows are average winds for November-December obtained from different datasets. Topographic contours every $250 \mathrm{~m}$, shaded above 1000 m. [Adapted from Garreaud et al. (2011).] 

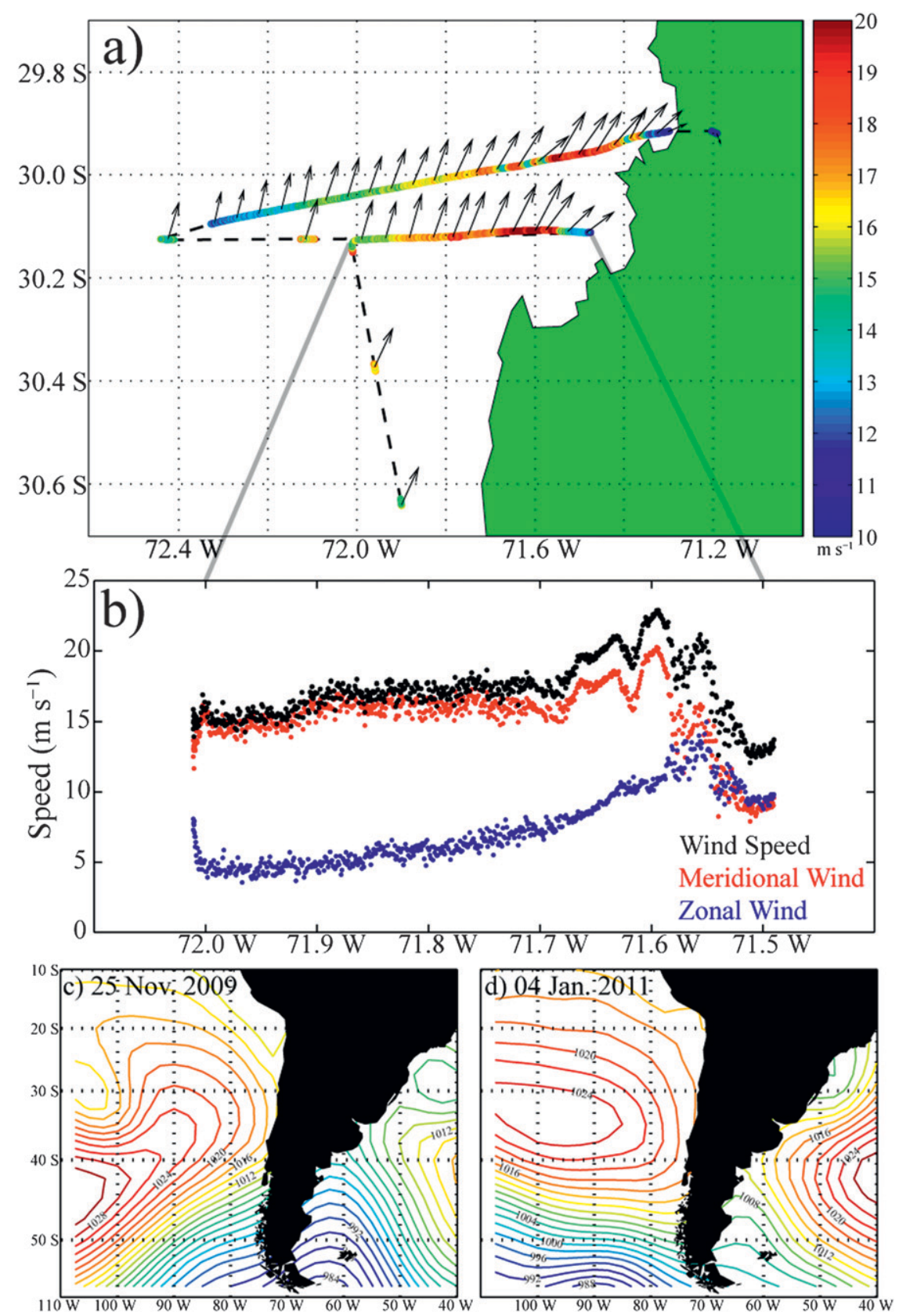

FIG. 5. Observations from an afternoon (1430-1600 LT) research flight on 4 Jan 2011 depicting (a) observed wind speed ( $\mathrm{m} \mathrm{s}^{-1}$, color) and vectors between 170-220 $\mathrm{m} \mathrm{ASL}$. (b) Wind components $\left(\mathrm{m} \mathrm{s}^{-1}\right)$ along the southernmost leg including the full wind speed (black), the meridional component (red), and the zonal component (blue) for the section indicated by the gray lines. Sea level pressure $(\mathrm{hPa})$ from National Centers for Environmental Prediction (NCEP) reanalysis on (c) 25 Nov 2009 and (d) 4 Jan 2011.

obtained by an afternoon (1430-1600 LT) research flight over TB on 4 January 2011 (Garreaud et al. 2011). Figure 5 depicts wind measurements during constant-level legs flown at $200 \pm 30 \mathrm{~m}$. Wind increased from about $12 \mathrm{~m} \mathrm{~s}^{-1}$ in the sheltered TB to $23 \mathrm{~m} \mathrm{~s}^{-1}$ just north of LdV and then decreased gradually offshore down to $15 \mathrm{~m} \mathrm{~s}^{-1}$ over the open ocean. Both the meridional and zonal components contributed to the wind speed maximum north of LdV. While the flight was not conducted during CUpEx (early summer 2009), the synoptic conditions during the flight (summer 2011) are similar. Specifically, the surface anticyclone is centered to the south of $35^{\circ} \mathrm{S}$ 

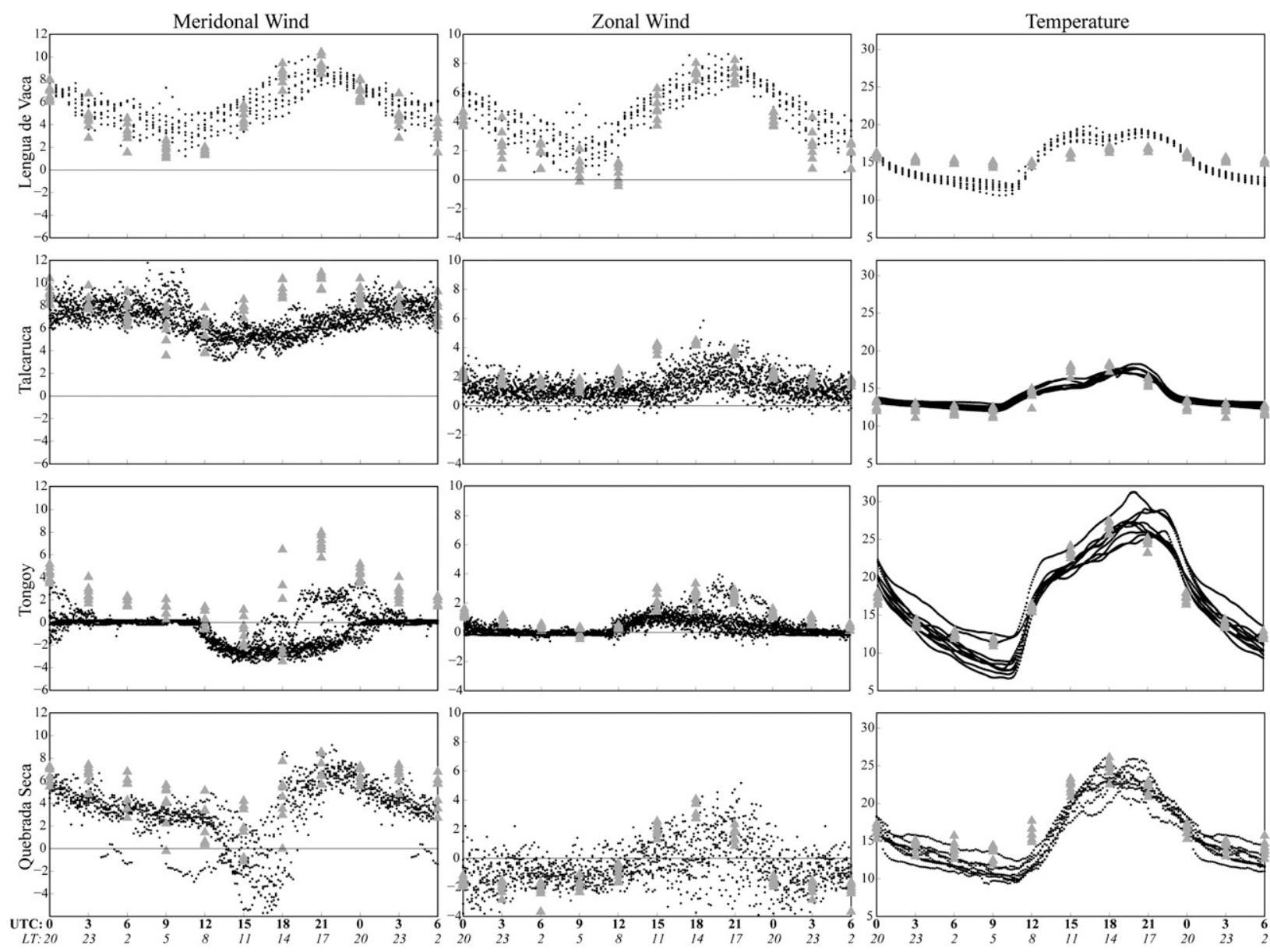

FIG. 6. Daily surface station (black) and model (gray) data during the high-wind period showing (left) meridional wind ( $\left.\mathrm{m} \mathrm{s}^{-1}\right),($ center) zonal wind $\left(\mathrm{m} \mathrm{s}^{-1}\right)$, and (right) temperature $\left({ }^{\circ} \mathrm{C}\right)$. Stations indicated on the left side. Time is in UTC (bold) and LT (italic).

leading to a southward-pointing SLP gradient along the coast (albeit stronger during mid-CUpEx) that favors southerly wind off central Chile (Muñoz and Garreaud 2005), and clear skies that foster the daytime heating inland (Figs. 5c,d). The afternoon wind maxima at LdV around the research flight day $\left(\sim 10 \mathrm{~m} \mathrm{~s}^{-1}\right.$, not shown) are similar to those observed during the high-wind period (cf. Fig. 3). The features during the flight are also similar to model results shown later.

More detailed data analysis is constrained to only the 8-day high-wind period that exhibited a very regular diurnal cycle (Garreaud et al. 2011). Two reasons for this restriction are 1) synoptic changes during the lowwind periods may obfuscate diurnal features and 2) the most comprehensive dataset is available for this period. Diurnal variation of temperature and wind over the 8-day period is shown for 4 key locations: TCR, $\mathrm{LdV}$, TGY, and QSC (Fig. 6).

LdV exhibits a considerable diurnal cycle in both wind components, which tend to vary in phase producing a maximum 30-min-averaged wind speed of $\sim 11 \mathrm{~m} \mathrm{~s}^{-1}$ near $1700 \mathrm{LT}$ and a minimum around $0600 \mathrm{LT}$. The temperature cycle is regulated by the adjacent ocean and ranges from $11^{\circ}$ to $20^{\circ} \mathrm{C}$. At TCR, onshore (zonal) wind peaks in the afternoon but it is relatively weak, presumably because of blocking by a nearby coastal cliff. The alongshore (meridional) wind is much stronger ( $>6 \mathrm{~m} \mathrm{~s}^{-1}$ at any time of the day) and steady, but exhibits a weak minimum from 1000 to 1800 LT. The temperature cycle is similar to $\mathrm{LdV}$ with a mean amplitude of only $7^{\circ} \mathrm{C}$.

Wind speed at TGY is much lighter, typically below $3 \mathrm{~m} \mathrm{~s}^{-1}$ and nighttime wind is calm. The dominant feature is a northwesterly sea breeze that develops early in the morning (around 0900 LT) and tends to last until sunrise (around 2000 LT). Nevertheless, on 5 days of the 8-day period, the northerly sea breeze was replaced by southerly wind (i.e., flow from the MT toward TB) during late afternoon. In spite of being adjacent to the sea, temperature at TGY ranges from $7^{\circ}$ to $29^{\circ} \mathrm{C}$. The 
zonal wind over the MT at QSC has a large spread, but the speed is typically $<2 \mathrm{~m} \mathrm{~s}^{-1}$. The meridional component is dominated by the southerly wind that reaches a maximum speed of $8 \mathrm{~m} \mathrm{~s}^{-1}$ around 1700 LT. From this afternoon maximum the southerly wind decreases gradually during night and early morning. Around 1100 LT, however, the southerly flow is suddenly replaced by northerly wind, simultaneous with an increase in specific humidity, signaling the arrival of the sea breeze commencing earlier at TGY. The timing and strength of the sea-breeze arrival at QSC, however, is very variable and only lasts for a few hours.

We can infer that the sea-land breeze originating over TB moves southward inland over the MT a few tens of kilometers during late morning and early afternoon, before being overcome by the opposing southerly wind that prevails along the subtropical coast, even though the MT is separated from the ocean by the $600-\mathrm{m}$-high Talinay Range (Fig. 2a).

The observations presented in Fig. 6 provide a stringent test to the WRF simulation. For the coastal stations (LdV and TCR), simulated cycles tend to agree with the observations in phase and amplitude, but the minimum wind speed is lower than observed and there is a smaller diurnal temperature range. The diurnal temperature change at $\mathrm{LdV}$ is smaller than the observations because the closest grid point to the surface station is actually over water. At TGY the simulated zonal wind is slightly stronger and temperatures do not reach the observed extrema. During the night the model southerly wind is greater than observed. Fortunately, the model also develops a sea-land breeze, but the northerly winds are always replaced by southerlies after 1700 LT. At QSC the model also captures the diurnal cycle, but simulates a much weaker sea breeze around midday.

\section{b. Tongoy soundings}

The average temperature profile during the high-wind period at TGY in the morning (0800 LT, Fig. 7a) includes a small surface layer that has just begun to develop due to solar heating, above which the temperature decreases by $6^{\circ} \mathrm{C} \mathrm{km}^{-1}$ until the base of a temperature inversion at $400 \mathrm{~m}$. The inversion layer extends up to about $1300 \mathrm{~m}$. During the day, there is a marked low-level warming (as large as $8^{\circ} \mathrm{C}$ at $500 \mathrm{~m}$ ) and by $1700 \mathrm{LT}$ the inversion base is at $980 \mathrm{~m}$. The lower part of the inversion layer has cooled slightly, and farther aloft $(>1200 \mathrm{~m})$ the afternoon and morning profiles are nearly identical. The afternoon low-level temperature profile exhibits considerable structure and it is far from a single well-mixed layer. Near the surface there is a shallow superadiabatic layer that becomes isothermal at $18.5^{\circ} \mathrm{C}$ up to $500 \mathrm{~m}$, follow by a layer with a constant lapse rate of $6^{\circ} \mathrm{C} \mathrm{km}^{-1}$ until reaching the temperature inversion. Such a complex vertical structure is indicative of several processes at play that we try to diagnose below. Moreover, we found that the morning to afternoon warming over TGY plays a role in enhancing the CJ north of LdV (see section 4c).

At TGY the zonal wind component below $1.5 \mathrm{~km}$ is light at both times (Fig. 7b), consistent with the weak near-surface zonal wind at TGY and QSC throughout the day (Fig. 6). The meridional flow is much stronger and changes substantially during the day. In the morning sounding, the wind is calm below $400 \mathrm{~m}$ but the southerlies increase in the inversion layer to reach a broad maximum at about $1000 \mathrm{~m}$. In the afternoon profile there are two distinctive layers. The daytime sea breeze is evident below $400 \mathrm{~m}$ (blowing from TB toward the MT), with maximum northerly flow $\left(3.5 \mathrm{~m} \mathrm{~s}^{-1}\right)$ near the surface. Above the sea breeze the southerly wind has increased relative to the morning sounding, with a sharper maximum of $7 \mathrm{~m} \mathrm{~s}^{-1}$ at $800 \mathrm{~m}$.

While there are no observations of the vertical structure above QSC, several conjectures can be posed. Recall that by 1700 LT (sounding time at TGY) the surface northerlies at QSC have been overridden by southerly winds that likely prevail in the whole column above this station. The very dry land around QSC is also conducive to the development of well-mixed boundary layer over the MT, consistent with the pronounced diurnal amplitude of the near-surface air temperature. The diabatically warmed air over the MT is subsequently advected northward (by the dominant southerly wind) above a cooler marine layer advected from the TB (by the shallow sea breeze). Later on, with the aid of a model-based trajectory analysis we have confirmed this opposing pattern of temperature advection below and above $400 \mathrm{~m}$. Also note that extrapolating the lapse rate of the residual layer at TGY down to the elevation of QSC gives a temperature close to the station record.

Therefore, we interpret the afternoon temperature profile at TGY as consisting of a lower marine layer (albeit strongly affected by surface sensible heating right at the coastline and vertical mixing around $400 \mathrm{~m}$ ) and a residual layer aloft advected from the dry, warm MT just to the south. The residual layer is not completely well mixed since the lapse rate is $6^{\circ} \mathrm{C} \mathrm{km}^{-1}$ instead of the dry adiabatic lapse rate, but is still a uniform layer. An alternative mechanism for the daytime low-level warming over TGY is enhanced leeside subsidence. Nevertheless, the highest topography is more than $100 \mathrm{~km}$ to the south of Tongoy (with the flat, low MT in between) and enhanced daytime subsidence should result in a warming of the inversion layer, in contrast with the observed slight cooling at the inversion level and no change aloft (Fig. 7a). 

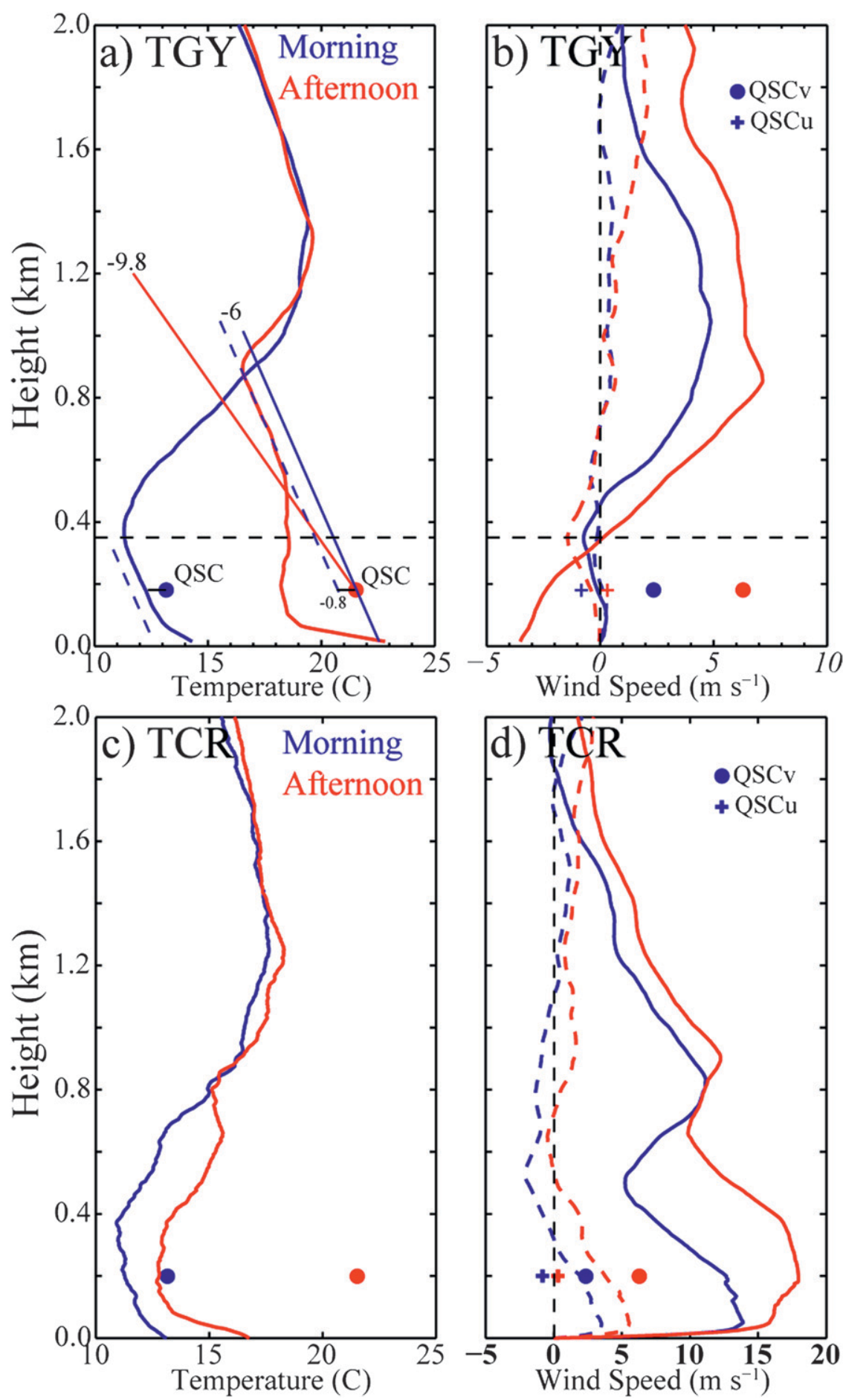

FIG. 7. Average soundings during the high-wind period at (a),(b) TGY and (c),(d) TCR. Blue (red) indicates morning (afternoon). In (a), lines with numbers above show an adiabatic $\left(9.8^{\circ} \mathrm{C} \mathrm{km}^{-1}\right)$ and $6^{\circ} \mathrm{C} \mathrm{km}^{-1}$ lapse rate. Note the different wind scales between TCR and TGY. Meridional (zonal) wind depicted by solid (dashed) lines in (b),(d). Averages at QSC are indicated by points at $180 \mathrm{~m}$. Meridional (zonal) wind at QSC is indicated by circle (cross). 

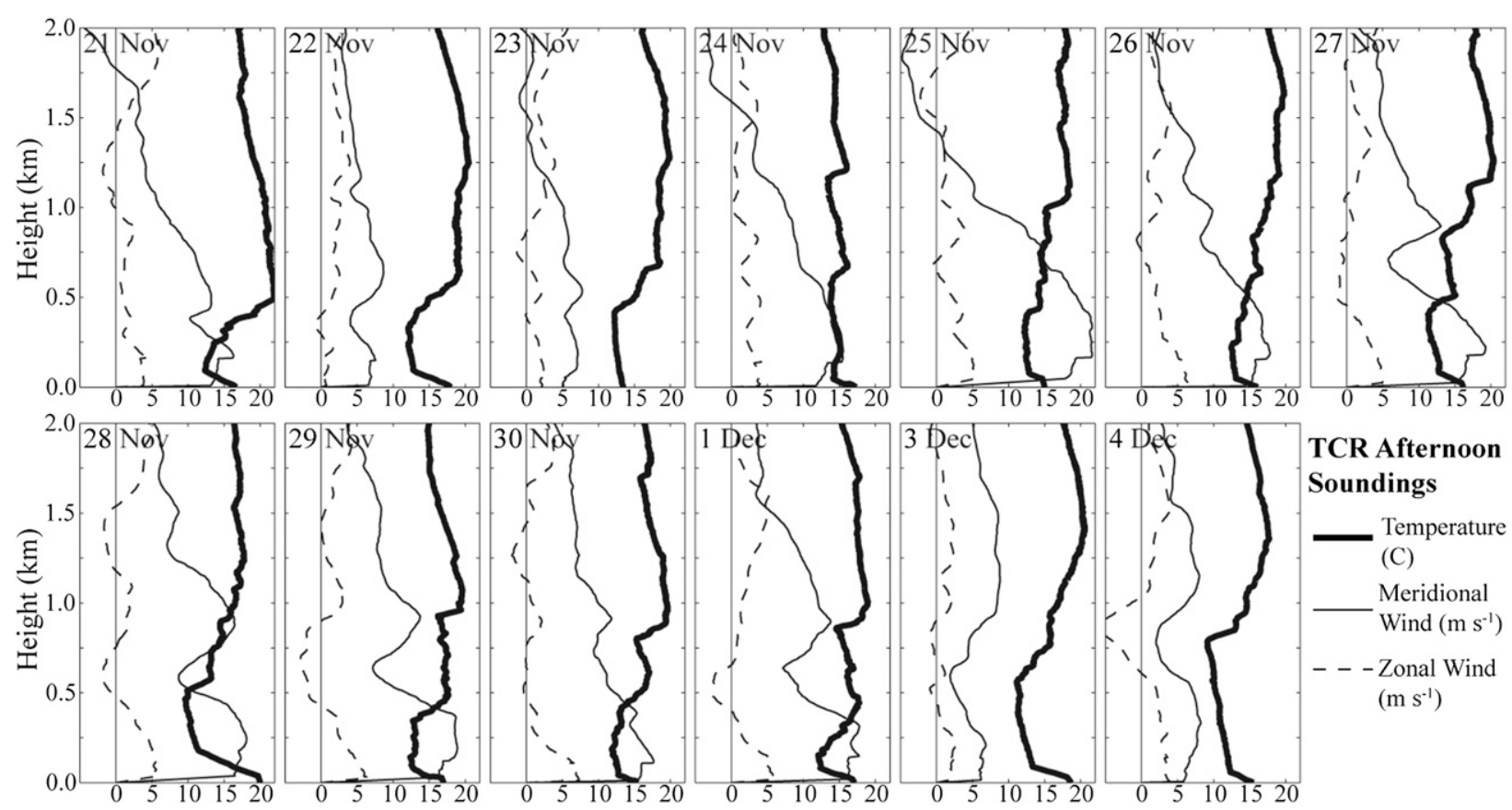

TCR Afternoon Soundings

Temperature (C) Meridional Wind $\left(\mathrm{m} \mathrm{s}^{-1}\right)$

- - Zonal Wind $\left(\mathrm{m} \mathrm{s}^{-1}\right)$

FIG. 8. Individual soundings from the afternoon radiosondes at TCR depicting temperature $\left({ }^{\circ} \mathrm{C}\right.$, bold), meridional wind ( $\mathrm{m} \mathrm{s}{ }^{-1}$, solid), and zonal wind ( $\mathrm{m} \mathrm{s}^{-1}$, dashed). Variables use the same scale on the $x$ axis and a vertical line is placed at 0 .

\section{c. Talcaruca soundings}

The average morning temperature profile at TCR resembles a typical coastal sounding (Fig. 7c). The AMBL exists under an inversion that has a base near $400 \mathrm{~m}$. The inversion layer, however, does not have a linear lapse rate as does the TGY morning sounding, but contains a point of minimum stability near $600 \mathrm{~m}$. The temperature profile becomes further destabilized in the afternoon producing two inversion layers separated by a near isothermal layer between 600 and $800 \mathrm{~m}$, at and just above the height of the nearby Altos de Talinay ridge. Wind profiles (Fig. 7d) also differ from the more classical coastal soundings and the depiction of the CJ (e.g., Burk and Thompson 1996) because there are two distinct wind maximum, one near the surface and one at $800-900 \mathrm{~m}$. The greatest diurnal changes occur in the alongshore component near the surface. The local minimum of meridional wind changes from $5 \mathrm{~m} \mathrm{~s}^{-1}$ near $500 \mathrm{~m}$ to $10 \mathrm{~m} \mathrm{~s}^{-1}$ near $700 \mathrm{~m}$, while the upper maximum increases $\sim 1 \mathrm{~m} \mathrm{~s}^{-1}$ and shifts upward from 800 to $900 \mathrm{~m}$.

Individual soundings at TCR contain much more variability than at TGY in the afternoon; in the morning, temperature profiles at TGY and TCR are similar. All 1700 LT soundings ${ }^{2}$ of the wind components and

\footnotetext{
${ }^{2}$ As a result of instrument failure, no sounding was obtained on 2 December.
}

potential temperature are depicted in Fig. 8. After the onset of the high-wind period during 27 November1 December, the double inversion/jet structure is clearly evident. As hinted in the average, the minimum meridional wind is associated with a layer of minimum stability and offshore wind (up to $2 \mathrm{~m} \mathrm{~s}^{-1}$ ). For example, on 29 November the most intense and thickest offshore flow layer is associated with the most marked and thickest destabilized layer above the lowest inversion.

The features described above do not appear unique to the coastal sounding at TCR. Two research flights in support of CUpEx included a meridional transect about $50 \mathrm{~km}$ off the coast between $32^{\circ}$ and $30^{\circ} \mathrm{S}$ (Garreaud et al. 2011) and detected the double jet structure (albeit weaker) found at TCR (not shown). This anomalous vertical structure would have implications for the application of two-layer hydraulic theory that is often invoked to describe coastal flow (e.g., Winant et al. 1988; Samelson 1992; Burk and Thompson 1996; Rogerson 1999; Burk et al. 1999; Haack et al. 2001). Specifically, multiple layers must be considered as well as the appropriate definition of the Froude number (particularly the phase speed of internal gravity waves). Unfortunately, the model is deficient in reproducing this secondary layer that spans only a few hundred meters. Without more zonal and vertical observations encompassing the region above MT and offshore or better modeling results, we have refrained from a more complete explanation and examination of this feature. 

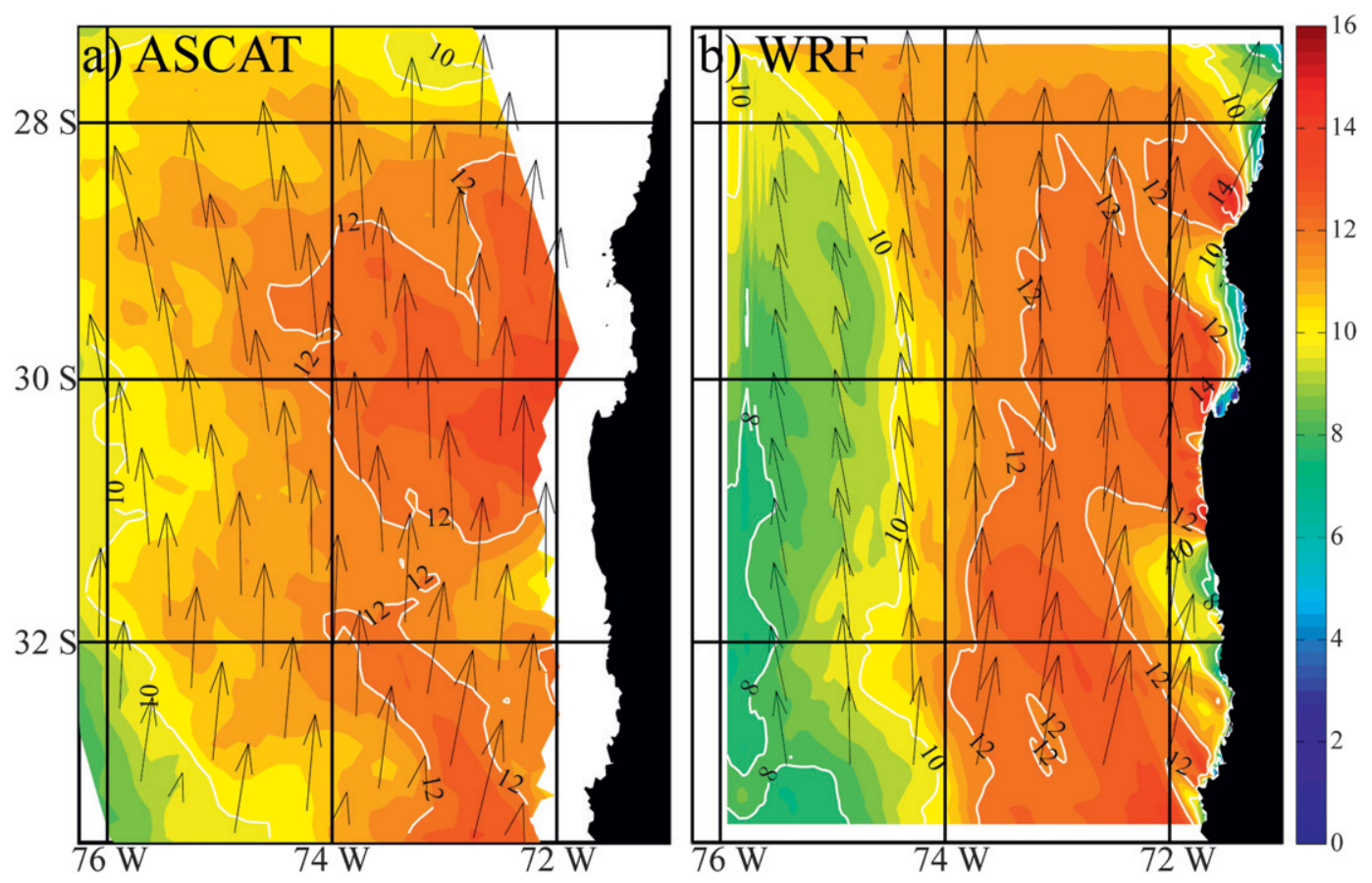

FIG. 9. The 10-m wind $\left(\mathrm{m} \mathrm{s}^{-1}\right)$ at 0000 UTC 1 Dec 2009 inferred from (left) ASCAT and from (right) WRF output.

\section{Model results}

Despite the model shortcomings, the WRF simulation still reasonably captures the dominant regional-scale features and supplements the observations by providing a broader context (including offshore and aloft) and allowing an environment in which to conduct sensitivity experiments. Focus is placed on the diurnal warming above TB and its influence on the $\mathrm{CJ}$ since these are robust features that the model captures.

\section{a. Simulated horizontal structure}

Figure 9 gives an example of the 10-m wind as inferred from the Advanced Scatterometer (ASCAT; FigaSaldaña et al. 2002) sensor and the WRF output. The LLJ during the field campaign tended to be similar in structure to the long-term averages (Fig. 1). A swath of high wind in the afternoon is located east of $74^{\circ} \mathrm{W}$, and a maximum is around $30^{\circ} \mathrm{S}$ near the coast. The intermittent coverage and blind spot of the satellite wind retrieval near the shore prevents more detailed inferences from this product. The simulation shows a similar magnitude and spatial distribution as ASCAT, but also reveals nearshore details. Wind maxima in the model appear north of Points Choros $\left(28.5^{\circ} \mathrm{S}\right), \mathrm{LdV}\left(30^{\circ} \mathrm{S}\right)$, and in the extreme southern part of the domain.

The modeled 10-m wind speed every $3 \mathrm{~h}$ (averaged during the CUpEx high-wind period) reveals a diurnally varying, complex horizontal distribution in the nearshore region (Fig. 10) and captures many features obtained from the station data (Fig. 4). At 0800 LT, the near-coastal winds are from the south, reach their minimum speed ( $11 \mathrm{~m} \mathrm{~s}^{-1}$ west of $\left.\mathrm{LdV}\right)$, and show little spatial variability outside of TB. Features change dramatically during the afternoon as there is a general increase in wind speed $\left(1-2 \mathrm{~m} \mathrm{~s}^{-1}\right)$ within $\sim 100 \mathrm{~km}$ of the coast and a localized maximum $\left(\sim 15 \mathrm{~m} \mathrm{~s}^{-1}\right)$ develops downwind of LdV. This simulated feature is precisely the CJ suggested by the observations (Figs. 1, 4, and 5). Recall that the $\mathrm{CJ}$ is distinguished separately from the broader LLJ that it is embedded in, although there are undoubtedly connections between the two, which are not directly explored here. The offshore wind increase is in agreement with long-term averages (Muñoz 2008), and is attributed to the diurnal change of baroclinicity in the coastal region (Burk and Thompson 1996). The local maximum in the lee of $\mathrm{LdV}$ is attributed to more local effects described below. Near-surface winds inland are also weakest during nighttime, and subsequently develop a sea breeze (Fig. 10). As noted before, the morning intrusion of the sea breeze from TB into the MT is not well resolved by the model. By 1400 LT strong southerlies prevails in the low lands south of TGY.

\section{b. Vertical structure}

Let us consider first the cross-shore structure at $30^{\circ} \mathrm{S}$, just north of LdV. In the morning (0800 LT, Fig. 11a) the southerly wind increases gradually offshore and is 

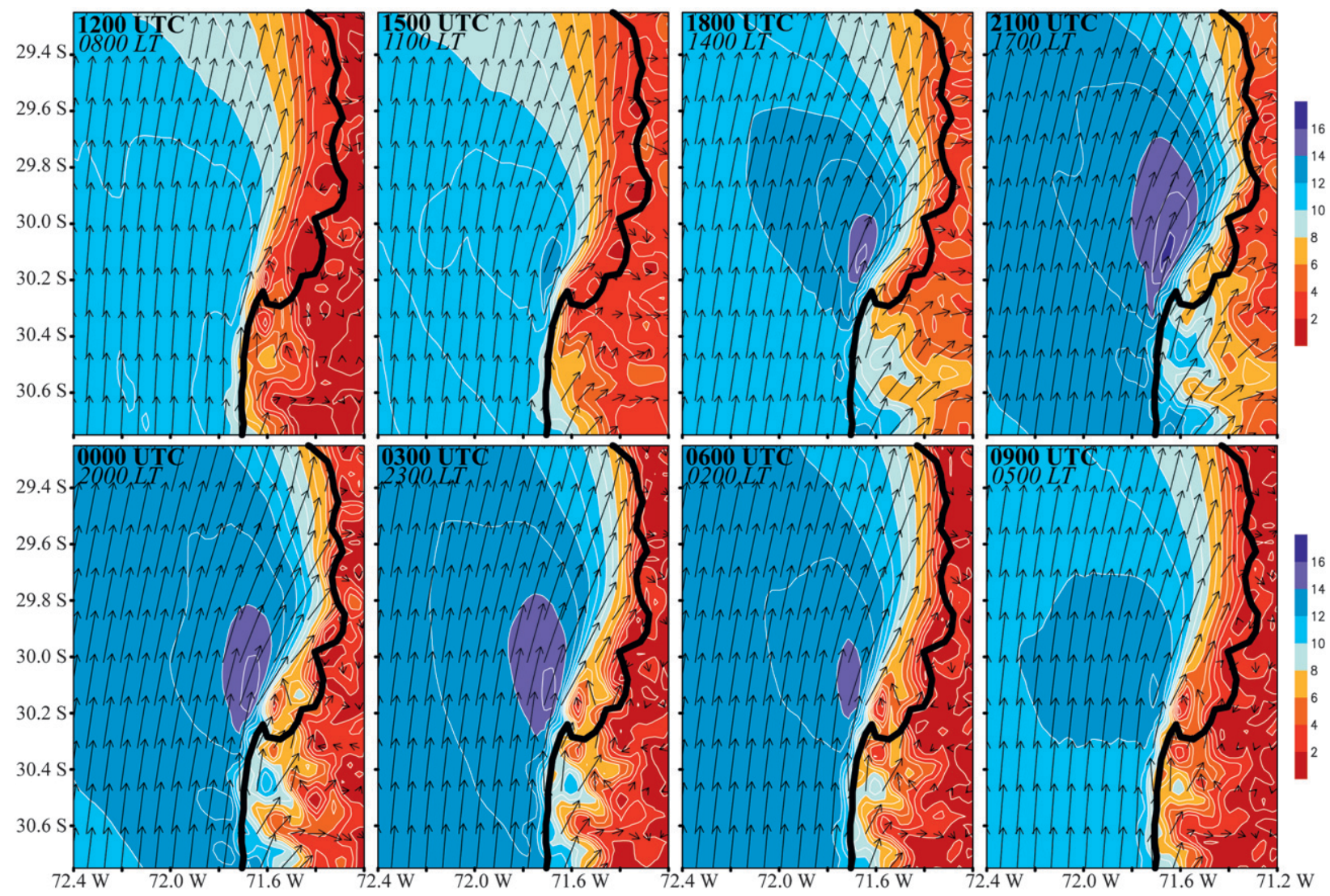

FIG. 10. Average simulated $10-\mathrm{m}$ wind $\left(\mathrm{m} \mathrm{s}^{-1}\right)$ during the high-wind period every $3 \mathrm{~h}$.

weakest over the sheltered TB (i.e., east of $71.7^{\circ} \mathrm{W}$ ). Likewise, the inversion base height exhibits a smooth increase offshore. From morning to afternoon the southerly wind increases and the high winds extend eastward into southern TB (Fig. 11b). At 1700 LT the CJ is evident just northwest of $\mathrm{LdV}$, with its core (maximum of $22 \mathrm{~m} \mathrm{~s}^{-1}$ ) located at the base of the inversion like the typical LLJ structure. While near-surface temperatures exhibit modest change (regulated by the ocean), the atmosphere above the AMBL warms considerably and is less stable. Maximum temperature change is $6 \mathrm{~K}$ in the center of the bay at $\sim 300 \mathrm{~m}$ (Fig. 11c). The temperature maximum is collocated with the location of the MT to the south, shown by the transparent green silhouette representing the topography along $30.4^{\circ} \mathrm{S}$. The greatest increase in wind speed is collocated with the enhanced zonal temperature gradient, and therefore one can infer an enhanced horizontal pressure gradient force.

A north-south cross section is taken directly over the MT along $71.53^{\circ} \mathrm{W}$ (Fig. 12). In the southern (left) half of the cross sections, changes in potential temperature and meridional wind are smaller than the large changes in the northern (right) half. True for the morning and afternoon, part of the southerly flow impinges on the terrain in the south and there is leeside flow indicated by the sharp gradient in potential temperature around $31^{\circ} \mathrm{S}$. North of the highest peak, the stability below $1 \mathrm{~km}$ decreases greatly during the day. Over the $100 \mathrm{~km}$ between the peak elevation and TB, the air over the dry land must also warm diabatically, mainly because of the large sensible heat flux as inferred from the QSC surface station and TGY sounding. The daytime solar heating not only contributes to a diabatic temperature change, but also impacts the flow over the peak by greatly destabilizing the downwind side. Recall that the afternoon residual layer height is near $1 \mathrm{~km}$ at TGY and there is no significant diurnal temperature change aloft. Separating leeside flow and the diabatic heating is difficult, but without the local daytime heating the downslope flow appears less intense, like in the morning. Later, a sensitivity test that increases the albedo is used to explore the role of daytime heating south of TB.

In the first $1.5 \mathrm{~km}$ above ground there is southerly wind on average. Moving northward at $5 \mathrm{~m} \mathrm{~s}^{-1}$ for $5 \mathrm{~h}$, an air parcel travels $90 \mathrm{~km}\left(\sim 0.8^{\circ}\right.$ of latitude). Assuming 

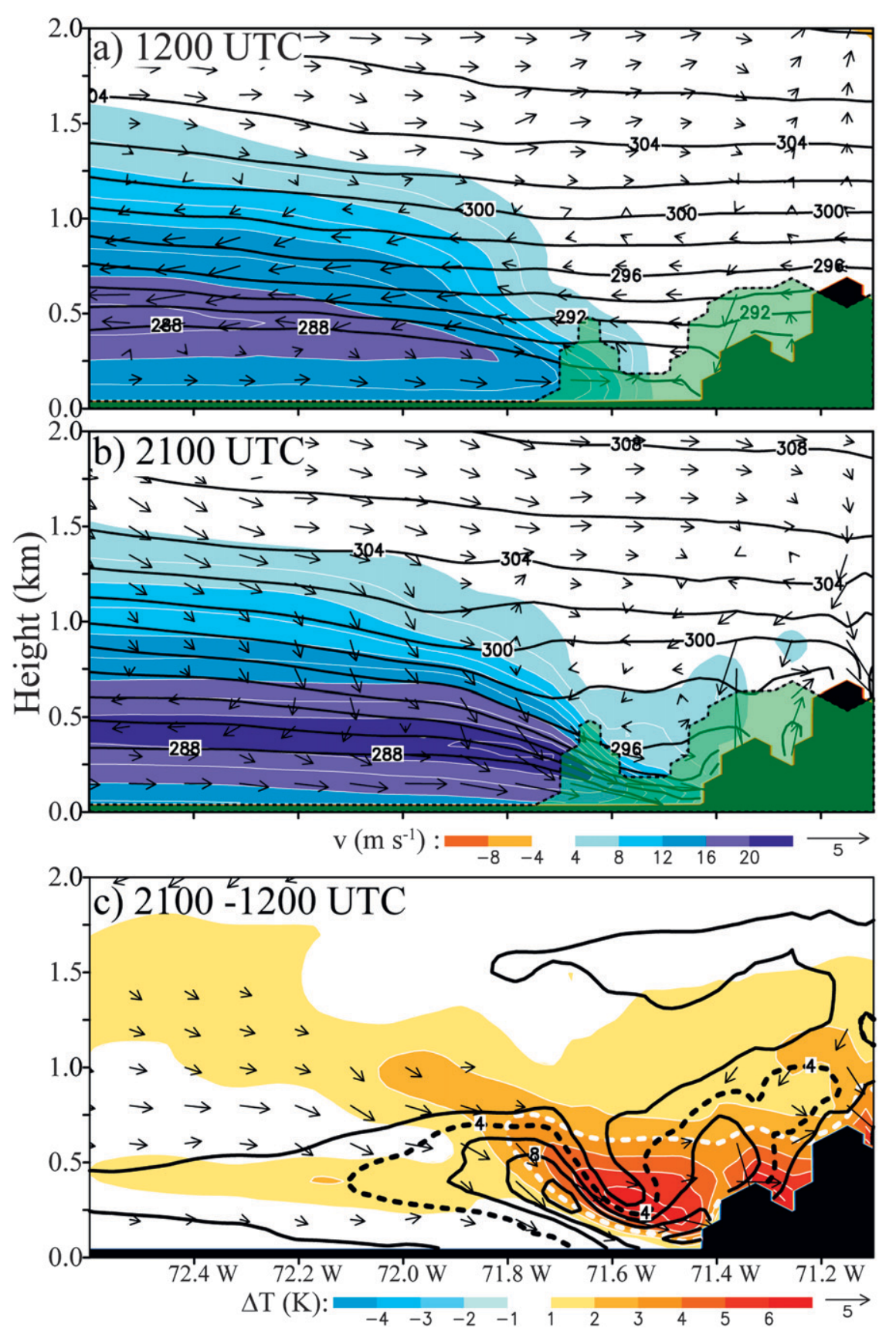

FIG. 11. Simulated meridional wind speed ( $\mathrm{m} \mathrm{s}^{-1}$, color), in-the-plane (u, w) vectors $\left[\mathrm{m} \mathrm{s}^{-1}\right.$, scale shown below (b)], and potential temperature (K, contours) along $30^{\circ} \mathrm{S}$ (terrain depicted by the solid black fill and terrain at $30.4^{\circ} \mathrm{S}$ depicted by transparent green silhouette) at (a) 1200 and (b) 2100 UTC. (c) 2100-1200 UTC potential temperature difference (K, color), meridional wind difference ( $\mathrm{m} \mathrm{s}^{-1}$, contours), and in-the-plane (u, w) vector difference $\left(\mathrm{m} \mathrm{s}^{-1}\right)$.

a meridional flow that is uniform, an air parcel reaching $30^{\circ} \mathrm{S}$ would have originated from over the terrain. Forward trajectories calculated with the model data using the Hybrid Single-Particle Lagrangian Integrated Trajectory model (HYSPLIT; Draxler and Rolph 2003) that begin at 1200 UTC 2 December above the MT $\left(30.4^{\circ} \mathrm{S}\right.$, $71.5^{\circ} \mathrm{W}$ ) are advected northward over $\mathrm{TB}$ while the lowest two trajectories are influenced by the sea breeze (Fig. 13a). Back trajectories that begin at 2100 UTC 2 December from $29.8^{\circ} \mathrm{S}, 71.5^{\circ} \mathrm{W}$ (central TB) reveal that 

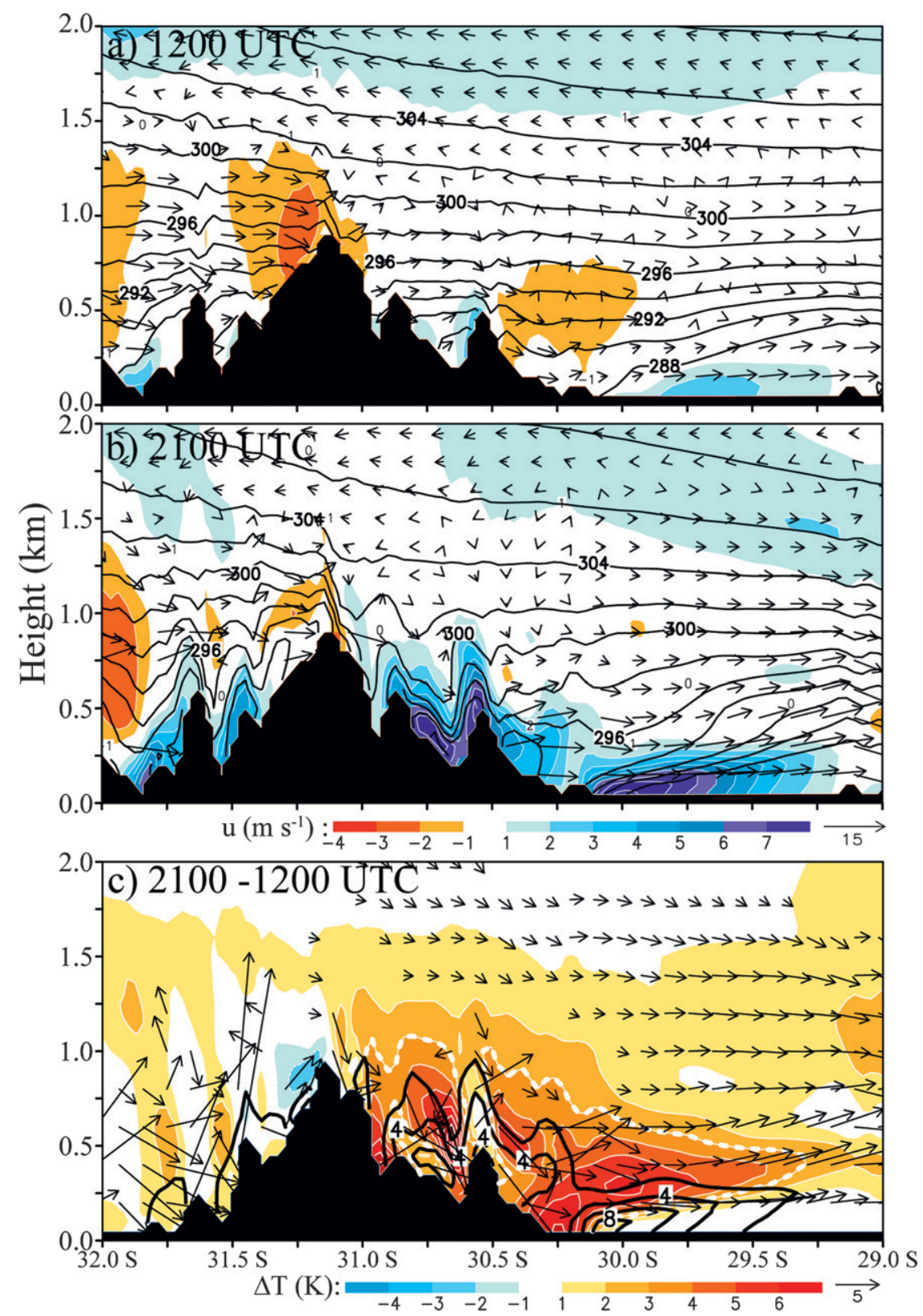

FIG. 12. Simulated zonal wind speed ( $\mathrm{m} \mathrm{s}^{-1}$, color), in-the-plane $(\mathbf{v}, \mathbf{w})$ vectors $\left[\mathrm{m} \mathrm{s}^{-1}\right.$, scale shown below (b)], and potential temperature (K, contours) along $71.53^{\circ} \mathrm{W}$ at (a) 1200 and (b) 2100 UTC. (c) 2100-1200 UTC potential temperature difference (K, color), zonal wind difference $\left(\mathrm{m} \mathrm{s}^{-1}\right.$, contours), and in-the-plane $(\mathbf{v}, \mathbf{w})$ vector difference $\left(\mathrm{m} \mathrm{s}^{-1}\right)$.

the lowest air parcels within the MBL come from around the cape, while just above the MBL they originate from over the MT south of TB (Fig. 13b). These model results are consistent with our previous interpretation of the complex daytime temperature profile over TGY.

\section{c. Low-level pressure field and CJ forcing}

Figure 14 illustrates the average surface pressure and 300-m temperature in the morning, afternoon, and their difference. In the morning both fields have a large zonal gradient just west of LdV, extending northward. Within TB the thermal gradient is primarily meridional. In the afternoon, the gradients intensify when warmer air (4$6 \mathrm{~K}$ ) extends in a swath $\sim 60 \mathrm{~km}$ north of LdV. The warm perturbation is confined to TB and does not extend westward of $71.7^{\circ} \mathrm{W}$, which is along the axis of the Altos de Talinay ridge. This indicates that the separation of the inland air from the offshore air by the topography 

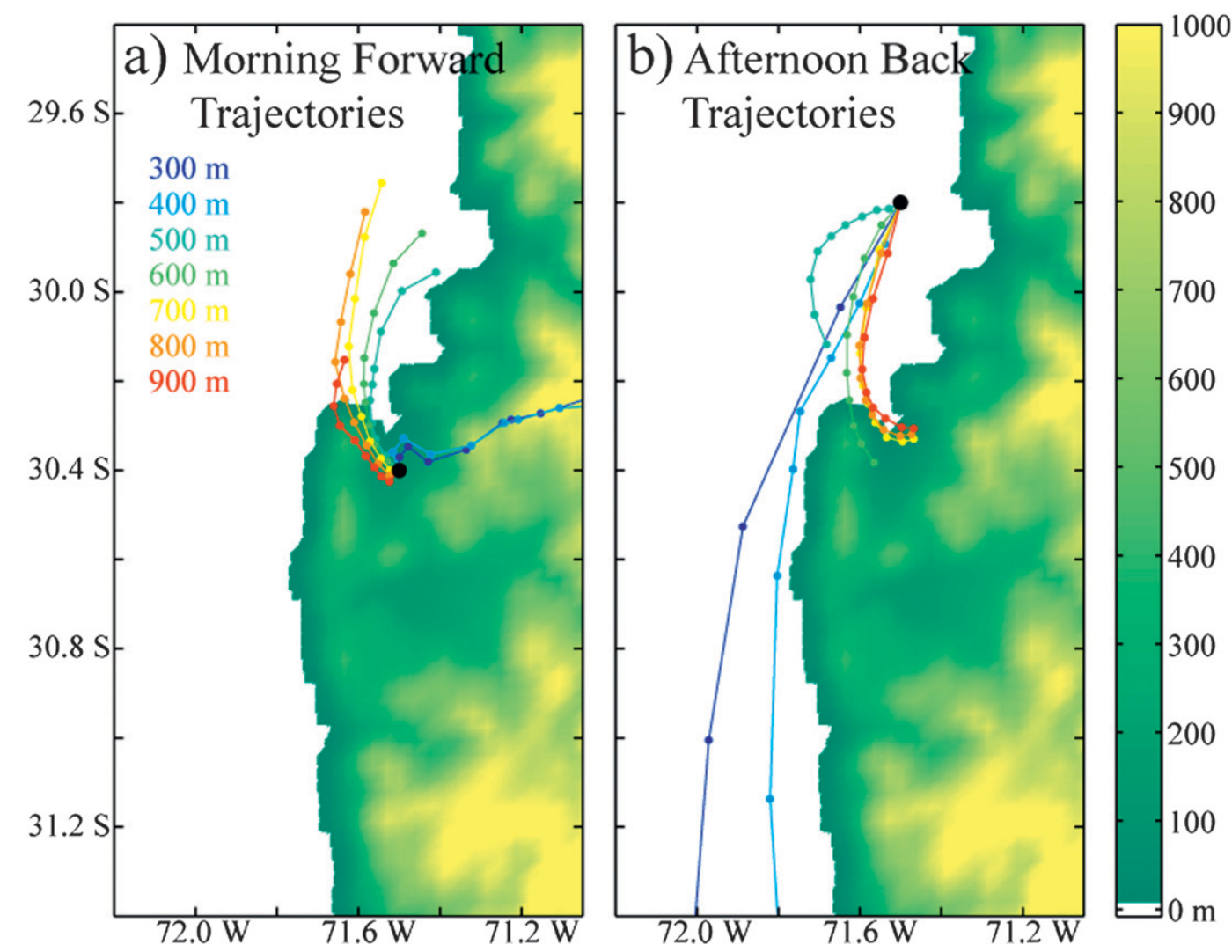

FIG. 13. On 2 Dec 2009 the 9 -h (a) forward trajectories from $30.4^{\circ} \mathrm{S}, 71.5^{\circ} \mathrm{W}$ beginning at $1200 \mathrm{UTC}(0800 \mathrm{LT})$, and (b) back trajectories beginning at $2100 \mathrm{UTC}(1700 \mathrm{LT})$ from $29.8^{\circ} \mathrm{S}, 71.5^{\circ} \mathrm{W}$. Initial parcel height indicated by color scale in (a). Elevation of topography $(\mathrm{m})$ indicated by color bar on right.

was effective and it was maintained as the air is advected northward of LdV (Fig. 14c).

The daily and average 2100-1200 UTC temperature profiles at TGY from the radiosondes and model are shown in Fig. 15a. The average change in the lowest $500 \mathrm{~m}$ is $>5 \mathrm{~K}$ and decreases steadily until $\sim 900 \mathrm{~m}$ where the temperature is cooler in a thin layer. Farther aloft, the temperature change is around zero. The model tends to have a smoother profile, because of more variability and not representing sharp vertical gradients well.

Associated with the change of temperature is a surface pressure decrease with the greatest magnitude in southern TB on the order of $1.6 \mathrm{hPa}$ (Fig. 14c). While simply heating an entire column would not change its surface pressure, replacing a 500-m-thick column with air that is $5 \mathrm{~K}$ warmer $(290-295 \mathrm{~K})$, a 1010-hPa surface pressure would decrease $\sim 1 \mathrm{hPa}$. This estimated hydrostatic change in pressure would account for $2 / 3$ of the pressure drop over TB (1 of $1.6 \mathrm{hPa}$ ), all else being equal. Other factors, such as replacing the air beyond a 500-m column (as is the case in the soundings below the inversion) or a change in the MBL depth (Dorman
1987), account for the additional 0.6-hPa drop from morning to afternoon. Pressure differences from the TGY soundings (Fig. 15b) show more variability, as indicated by the standard deviation, but the profiles during the high-wind period are similar. The change in pressure is constant aloft (including above $2.5 \mathrm{~km}$ ) until a kink in the lower elevations. The uniform shift of the pressure in the entire column is attributed to the diurnal pressure tide (e.g., Fuenzalida 1996), which WRF does not simulate. The pressure difference is also calculated using the hypsometric equation starting at $2.5 \mathrm{~km}$ and integrating down using the observed temperatures (red line). Its profile agrees quite well with the actual (and simulated) pressure change, even without considering any other influence on the pressure change. Model pressure change is smoother, similar to the model temperature change, but still produces reasonable results.

Because the diurnal cycle over TB is greater than out west over the ocean, a corresponding change in the local horizontal pressure gradient force (PGF) will drive the acceleration of the wind. The ageostrophic wind $\left(\mathbf{V}_{a}\right)$, a representation of acceleration, is useful to help diagnose 

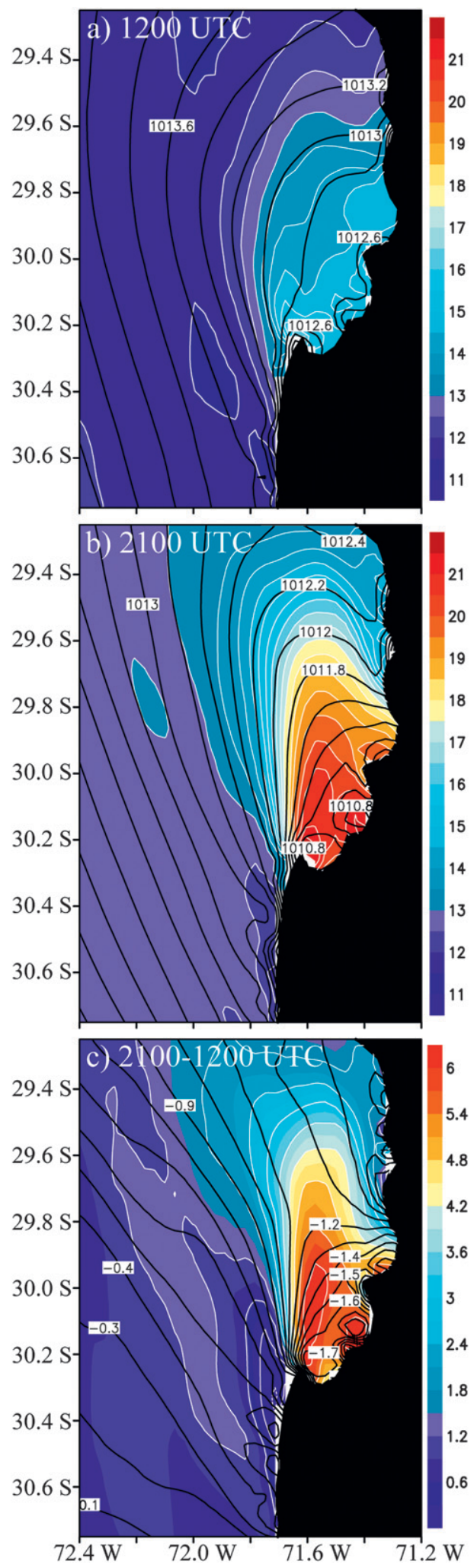

FIG. 14. Simulated surface pressure ( $\mathrm{hPa}$, contour) and $300-\mathrm{m}$ temperature $\left({ }^{\circ} \mathrm{C}\right.$, color) at (a) 1200 , (b) 2100 , and (c) 2100-1200 UTC. the sources of the wind changes and are described by the following equation that separates $\mathbf{V}_{a}$ into two components, where $\mathbf{V}_{g}$ is the geostrophic wind and $f$ is the Coriolis parameter (Holton 2004):

$$
\mathbf{V}_{a}=\frac{1}{f}\left[\mathbf{k} \times\left(\mathbf{V}_{g} \cdot \nabla\right) \mathbf{V}_{g}+\mathbf{k} \times \frac{\partial \mathbf{V}_{g}}{\partial t}\right] .
$$

The first term on the right is the advective component that represents the horizontal advection of $\mathbf{V}_{g}$ by itself. The second term is the isallobaric component that represents the acceleration due to changes of the PGF (geopotential height gradient) over time. Figure 16 illustrates the 3-h change in geopotential height, the two ageostrophic wind components, and the acceleration of the wind at $1000 \mathrm{hPa}$ for 0900 and 1500 UTC (0500 and 1100 LT) 1 December 2009. Note that acceleration due to the ageostrophic wind components is $90^{\circ}$ to the left of the ageostrophic wind direction in the Southern Hemisphere.

Above TB the greatest height increase (decrease) takes place over night (late morning). Because the localized pressure changes in TB are greater than the changes happening to the west, the region between TB and the open ocean displays a strong change in the geopotential height gradient over time. This is well represented by the isallobaric component of the ageostrophic wind that reverses from $25 \mathrm{~m} \mathrm{~s}^{-1}$ from the east predawn (0500 LT) to $25 \mathrm{~m} \mathrm{~s}^{-1}$ from the west during late morning (1100 LT). Thus, accelerations associated with the isallobaric component change from northward in the daytime and southward in the nighttime. The advective component is greatest when there is a large gradient in geostrophic wind speed, which occurs during the day, and is directed to the southeast over most of the domain. Here, it appears that the isallobaric component (changes in the PGF), driven by the large diurnal temperature changes aloft that originate from the valley to the south, is a fairly large contributor to the diurnal acceleration. A large isallobaric component at $\mathrm{LdV}$ is in contrast to the nearly total dominance of the advective component during a strong $\mathrm{CJ}$ in the lee of Cape Mendocino in northern California where the isallobaric component at the same local time of day (1100 LT) and level (1000 hPa) as in Fig. 12, is light $\left[<5 \mathrm{~m} \mathrm{~s}^{-1}\right.$, cf. Fig. 13 in Rahn and Parish (2007)].

\section{d. Sensitivity experiment}

Several factors may contribute to the intensity of the CJ. To highlight the role of the daytime heating over the arid land south of TB, the surface albedo is increased to $75 \%$ (Fig. 17a). Over the MT, the reduction in effective solar energy decreases the mean maximum surface air temperature from $25^{\circ} \mathrm{C}$ in the control run to $18^{\circ} \mathrm{C}$ in the sensitivity experiment. While various comparisons may 

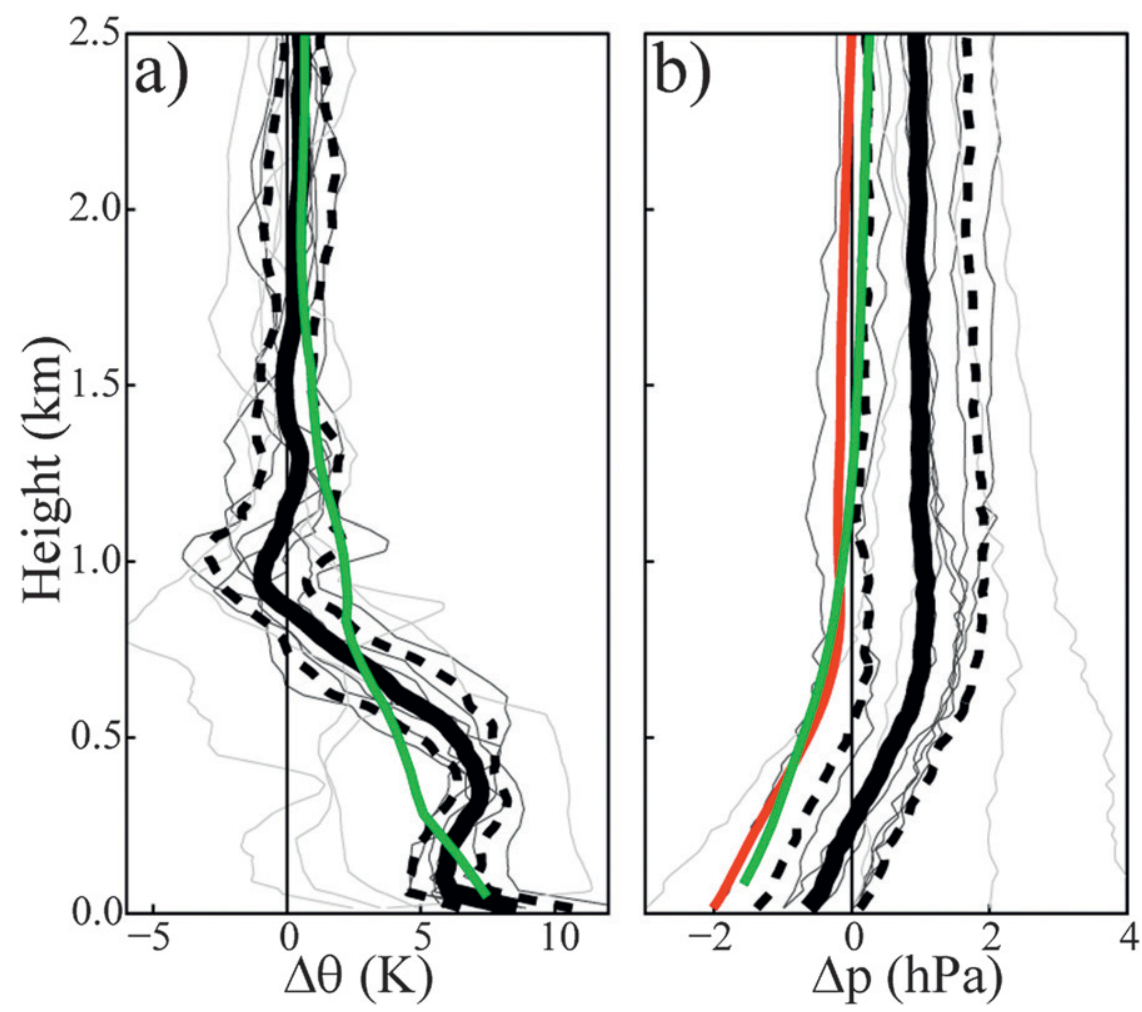

FIG. 15. Diurnal difference (2100-1200 UTC) of (a) potential temperature (K) and (b) pressure $(\mathrm{hPa})$. Individual daily differences are shown by thin lines during the high-wind period (black) and low-wind period (gray). The thick black lines are the average during the high-wind period and dashed lines indicate \pm one standard deviation. Green lines are the model average during the high-wind period. The red line is the pressure difference calculated hydrostatically from the observed temperature difference.

be shown, only the average cross-shore section along $30^{\circ} \mathrm{S}$ and $71.5^{\circ} \mathrm{W}$ of the afternoon minus morning difference are selected since these highlight the key differences related to the daytime CJ maximum. While well offshore the $2 \mathrm{~m} \mathrm{~s}^{-1}$ increase of wind is similar to the control (Fig. 17b), temperature and meridional wind changes over TB are $3 \mathrm{~K}$ and $5 \mathrm{~m} \mathrm{~s}^{-1}$ as opposed to $6 \mathrm{~K}$ and $10 \mathrm{~m} \mathrm{~s}^{-1}$ as in the control run. The maximum meridional wind speed at the CJ core is reduced from $22 \mathrm{~m} \mathrm{~s}^{-1}$ in the control run to $19 \mathrm{~m} \mathrm{~s}^{-1}$ in the sensitivity experiment. The diurnal change of zonal wind over TB decreases from $8 \mathrm{~m} \mathrm{~s}^{-1}$ in the control to $4 \mathrm{~m} \mathrm{~s}^{-1}$ in the sensitivity experiment (Fig. 17c). The suppressed diurnal cycle of near surface air temperature in the valley to the south reveals that it contributes to the warm air over TB and that the intensity of the $\mathrm{CJ}$ is enhanced by the daytime surface heating to the south.

\section{Summary}

Using observations from a dedicated field campaign (VOCALS-CUpEx) and a high-resolution numerical simulation (WRF), we described the low-level, mesoscale circulation features around point Lengua de Vaca (LdV)-Tongoy bay (TB) at $30^{\circ} \mathrm{S}$, one of the most important upwelling centers along the Chilean coast. We focus on a weeklong period of strong winds and regular diurnal cycles at the end of November 2009. The average conditions during this period are close to climatology. The key results are as follows:

- At TCR, in the straight north-south coastline about $25 \mathrm{~km}$ south (upstream) of LdV, morning soundings reveal a typical AMBL capped by a temperature inversion with a base near $400 \mathrm{~m}$, but the meridional wind profile is atypical with a distinctive wind minimum at $500 \mathrm{~m}$.

- The average afternoon temperature profile at TCR often included a destabilized layer bounded by two temperature inversions. This is an important deviation from an idealized two-layer model of the AMBL that is often used to address hydraulic effects along the coast such as compression bulges and expansion fans (e.g., Burk and Thompson 1996; Haack et al. 2001). Without 

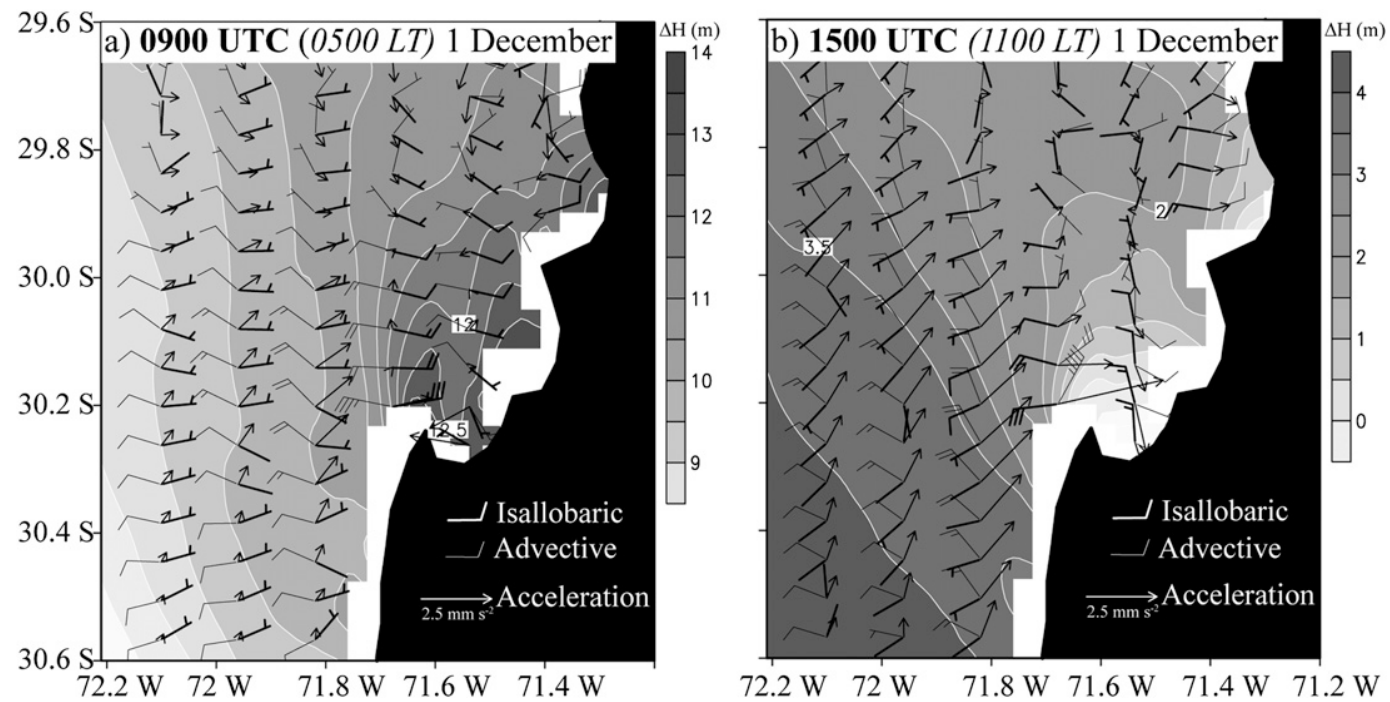

FIG. 16. Simulated acceleration (vectors, $\mathrm{mm} \mathrm{s}^{-2}$ ), isallobaric wind (bold barbs), and advective wind (normal barbs) components $\left(\mathrm{m} \mathrm{s}^{-1}\right.$ ) at $1000 \mathrm{hPa}$ for (a) 0900 UTC 1 Dec and (b) 1500 UTC 1 Dec 2009. Change of geopotential height $(\mathrm{m})$ over the previous $3 \mathrm{~h}$ indicated by white contours and grayscale.

a more complete dataset, the offshore/alongshore extent, frequency, and origin of this double jet/double inversion structure are unclear. Dedicated observations are required to better understand these features and warrant future study.

- Conditions over the gently sloping, dry marine terrace (MT) south of TB were recorded at the surface station at QSC, which exhibited a southerly wind most of the time with the exception of a weak sea breeze in the late morning commencing earlier at TGY right at the southern end of the bay.

- Afternoon soundings at TGY exhibit a pronounced daytime warming with a complex structure, reflecting the interaction of the sea breeze and wind originating
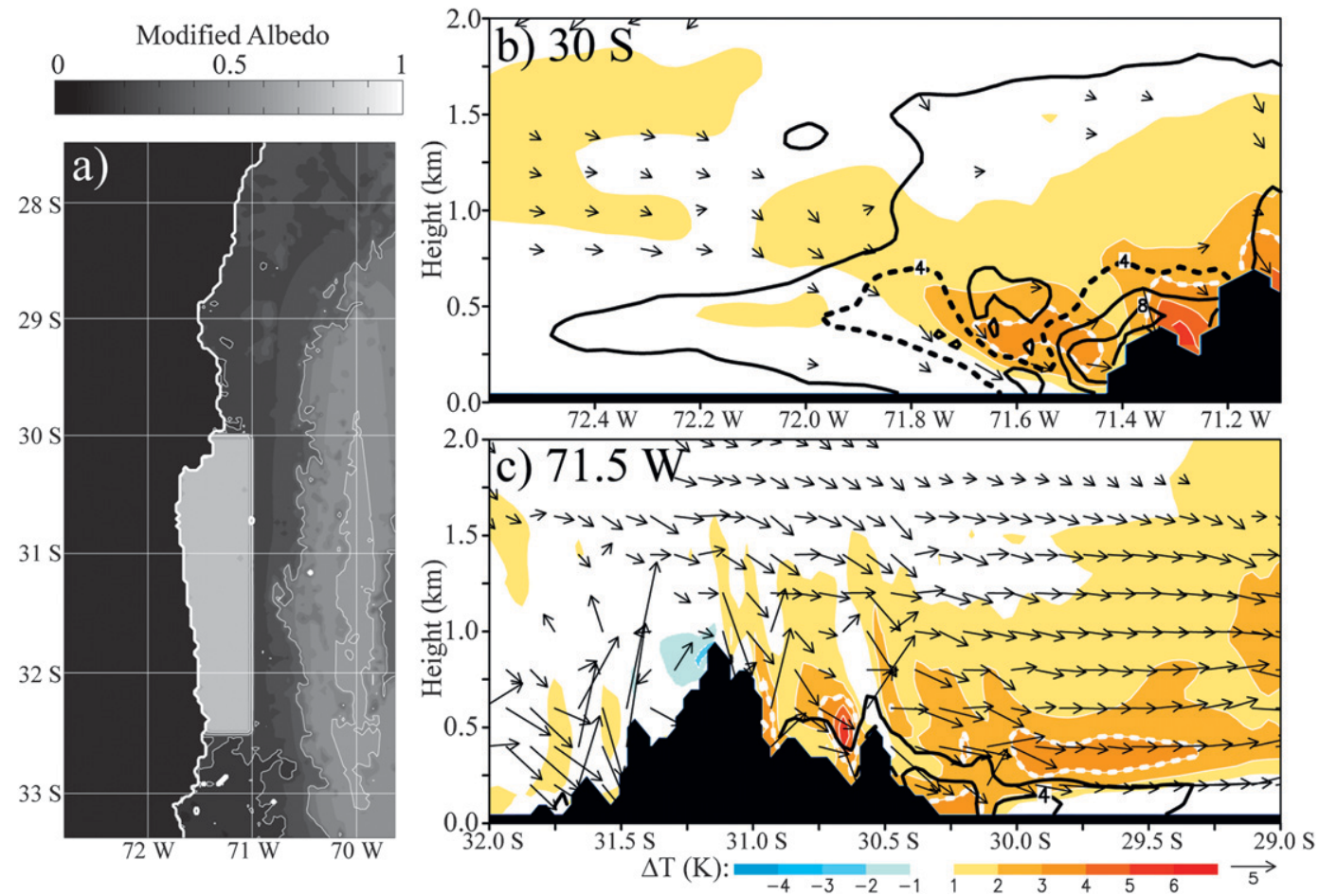

FIG. 17. (a) Map of modified albedo (\%). (b),(c) As in Figs. 11c and 12c, but from the high albedo simulation. 
from the south over the MT. An isothermal layer associated with the sea breeze exists up to $\sim 400 \mathrm{~m}$ above a shallow, superadiabatic surface layer. Between $500 \mathrm{~m}$ and the temperature inversion at $980 \mathrm{~m}$ there is a steady lapse rate of $6^{\circ} \mathrm{C} \mathrm{km}^{-1}$. This is likely a residual boundary layer advected from the south over the $100 \mathrm{~km}$ distance between the highest peak and TB that was likely influenced over its journey by both diabatic heating and leeside warming from enhanced subsidence during the day.

- The strongest surface winds (and the largest diurnal cycle) are observed around $1700 \mathrm{LT}$ at the LdV surface station, located between the warmer daytime air over TB and the cooler air offshore.

- Even with the blind zone near the coast, long-term satellite data suggests a CJ just north of LdV that is not evident in the morning. Aircraft data confirms the existence of a daytime CJ and model results corroborate that a narrow, intense $\mathrm{CJ}$ extends north from LdV from midday to sunset.

- Local, daytime baroclinicity enhances the development of the CJ that develops from the northward advection of diabatically/subsidence heated continental air over TB. For reference, a layer about $500 \mathrm{~m}$ thick and $5 \mathrm{~K}$ warmer that replaces the cooler air column in the morning in the southern portion of TB would be associated with a local surface pressure drop of $\sim 1 \mathrm{hPa}$ inducing a strong ageostrophic acceleration of the flow.

- A sensitivity test that increased the albedo to $75 \%$ only over the land south of TB showed a reduction in the daytime wind maximum, illustrating the contribution of the daytime heating over the MT for intensifying the CJ.

The conditions documented in this work are likely representative of the moderate-to-strong wind regimes that prevail along the central Chile coast in spring and summer. The complex, diurnally varying local wind is a major driver of the ocean circulation in TB through wind stress and wind stress curl east of the jet axis, and regional ocean modeling is now under way to assess the actual role of the CJ in upwelling dynamics. While CJs have had much work over the past few decades, the uniqueness of the LdV-TB region is helpful in advancing our understanding of coastal forcing mechanisms.

Acknowledgments. This work was supported by FONDECYT Grant 1090492, and the Department of Geophysics, Universidad de Chile. Radiosondes at Talcaruca were supported by the Comisión Nacional de Energía. We thank the Dirección Meteorológica de Chile and, in particular, to José Nuñez for the soundings at Tongoy, and Marcelo Ibarra for his help at Talcaruca. We are grateful to the village of Talcaruca, in particular to the president of the Fishermen Union, Mrs. Bernarda Campusano, for their hospitality during the field campaign. Dr. Ricardo C. Muñoz is thanked for his helpful insights and in producing Fig. 4. Meteorological information from Quebrada Seca weather station was kindly provided by Sonia Montecinos through project FONDEF D05I210038 to CEAZA-ULS.

\section{REFERENCES}

Burk, S. D., and W. T. Thompson, 1996: The summertime low-level jet and marine boundary layer structure along the California coast. Mon. Wea. Rev., 124, 668-686.

_ _ T. Haack, and R. M. Samelson, 1999: Mesoscale simulation of supercritical, subcritical, and transcritical flow along coastal topography. J. Atmos. Sci., 56, 2780-2795.

Dorman, C. E., 1987: Possible role of gravity currents in northern California's coastal summer wind reversals. J. Geophys. Res., 92, 1497-1506.

Draxler, R. R., and G. D. Rolph, cited 2003: HYSPLIT (Hybrid Single-Particle Lagrangian Integrated Trajectory) Model. NOAA/Air Resources Laboratory, Silver Spring, MD. [Available online at http://ready.arl.noaa.gov/HYSPLIT.php.]

Dudhia, J., 1989: Numerical study of convection observed during the winter monsoon experiment using a mesoscale two-dimensional model. J. Atmos. Sci., 46, 3077-3107.

Figa-Saldaña, J., J. J. W. Wilson, E. Attema, R. Gelsthorpe, M. R. Drinkwater, and A. Stoffelen, 2002: The Advanced Scatterometer (ASCAT) on the meteorological operational (MetOp) platform: A follow on for European wind scatterometers. Can. J. Remote Sens., 28, 404-412.

Figueroa, D., and C. Moffat, 2000: On the influence of topography in the induction of coastal upwelling along the Chilean Coast. Geophys. Res. Lett., 27(23), 3905-3908.

Fuenzalida, H. A., 1996: Daily cycle of sea-level atmospheric pressure around $30^{\circ} \mathrm{S}$ over the Chilean coast. Beitr. Phys. Atmos., 69, $1-5$.

Garreaud, R. D., and R. Muñoz, 2005: The low-level jet off the subtropical west coast of South America: Structure and variability. Mon. Wea. Rev., 133, 2246-2261.

_ CIMAR-5: A snapshot of the lower troposphere over the subtropical southeast Pacific. Bull. Amer. Meteor. Soc., 82, 2193-2207. ,$- \ldots$, and H. Fuenzalida, 2002: Coastal lows in north-central Chile: Mean structure and evolution. Mon. Wea. Rev., 130,75-88.

_ J. A. Rutllant, R. C. Muñoz, D. A. Rahn, M. Ramos, and D. Figueroa, 2011: VOCALS-CUpEx: The Chilean Upwelling Experiment. Atmos. Chem. Phys., 11, 2015-2029.

González, C., J. Rutllant, and P. Paolini, 2007: Frecuencia y albedo de estratocúmulos costeros entre Paposo $\left(24,5^{\circ} \mathrm{S}\right)$ y Papudo $\left(32,5^{\circ} \mathrm{S}\right)$ para el período 1998-2002. (Frequency and albedo of coastal stratocumulus between Paposo $\left(24.5^{\circ} \mathrm{S}\right)$ and Papudo $\left(32.5^{\circ} \mathrm{S}\right)$ for the period 1998-2002). Cuarto Taller de Trabajo sobre la Circulación Oceánica y Atmosférica en la Región del Pacifico Suroriental (Fourth Workshop on Ocean and Atmospheric Circulation in the Southeast Pacific Region), Santiago, Chile, Comité Oceanográfico Nacional.

Haack, T., S. D. Burk, C. Dorman, and D. Rodgers, 2001: Supercritical flow interaction within the Cape Blanco-Cape Mendocino orographic complex. Mon. Wea. Rev., 129, 688-708. 
Hill, A. E., B. M. Hickey, F. A. Shillington, P. T. Strub, K. H. Brink, E. D. Barton, and A. C. Thomas, 1998: Eastern ocean boundaries. The Sea, A. R. Robinson and K. H. Brink, Eds., The Global Coastal Ocean: Regional Studies and Syntheses, Vol. 11, John Wiley and Sons, 29-67.

Holton, J. R., 2004: An Introduction to Dynamic Meteorology. 4th ed. Elsevier, 529 pp.

Janjić, Z. I., 2000: Comments on "Development and evaluation of a convection scheme for use in climate models." J. Atmos. Sci., 57, 3686-3686.

_ 2002: Nonsingular implementation of the Mellor-Yamada level 2.5 scheme in the NCEP Meso model. NCEP Office Note 437, $61 \mathrm{pp}$.

Jiang, Q., S. Wang, and L. O’Neill, 2010: Some insights into the characteristics and dynamics of the Chilean low-level coastal jet. Mon. Wea. Rev., 138, 3185-3206.

Klein, S. A., and D. L. Hartmann, 1993: The seasonal cycle of low stratiform clouds. J. Climate, 6, 1587-1606.

Mlawer, E. J., S. J. Taubman, P. D. Brown, M. J. Iacono, and S. A. Clough, 1997: Radiative transfer for inhomogeneous atmosphere: RRTM, a validated correlated-k model for the longwave. J. Geophys. Res., 102 (D14), 16 663-16 682.

Muñoz, R. C., and R. D. Garreaud, 2005: Dynamics of the low-level jet off the west coast of subtropical South America. Mon. Wea. Rev., 133, 3661-3677.

- 2008: Diurnal cycle of surface winds over the subtropical southeast Pacific. J. Geophys. Res., 113, D13107, doi:10.1029/ 2008JD009957.

Perlin, N., E. D. Skyllingstad, and R. M. Samelson, 2011: Coastal atmospheric circulation around an idealized CAPE during winddriven upwelling studied from a coupled ocean-atmosphere model. Mon. Wea. Rev., 139, 809-829.
Pleim, J. E., and A. Xiu, 2003: Development of a land surface model. Part II: Data assimilation. J. Appl. Meteor., 42, 18111822.

Rahn, D. A., and T. R. Parish, 2007: Diagnosis of the forcing and structure of the coastal jet near Cape Mendocino using in situ observations and numerical simulations. J. Appl. Meteor. Climatol., 46, 1455-1468.

, and R. Garreaud, 2010a: Marine boundary layer over the subtropical southeast Pacific during VOCALS-REx-Part 1: Mean structure and diurnal cycle. Atmos. Chem. Phys., 10, 4491-4506.

— southeast Pacific during VOCALS-REx-Part 2: Synoptic variability. Atmos. Chem. Phys., 10, 4507-4519.

Rogerson, A. M., 1999: Transcritical flows in the coastal marine atmospheric boundary layer. J. Atmos. Sci., 56, 2761-2779.

Samelson, R. M., 1992: Supercritical marine-layer flow along a smoothly varying coastline. J. Atmos. Sci., 49, 1571-1584.

Skamarock, W. C., J. B. Klemp, J. Dudhia, D. O. Gill, D. M. Barker, W. Wang, and J. G. Powers, 2005: A description of the advanced research WRF version 2. NCAR Tech. Note NCAR/TN$468+$ STR, 88 pp.

Söderberg, S., and M. Tjernström, 2002: Diurnal cycle of supercritical along-coast flows. J. Atmos. Sci., 59, 2615-2624.

Thompson, G., R. M. Rasmussen, and K. Manning, 2004: Explicit forecasts of winter precipitation using an improved bulk microphysics scheme. Part I: Description and sensitivity analysis. Mon. Wea. Rev., 132, 519-542.

Winant, C. D., C. E. Dorman, C. A. Friehe, and R. C. Beardsley, 1988: The marine boundary layer off northern California: An example of supercritical channel flow. J. Atmos. Sci., 45, 3588-3605. 